\title{
Molecular Design of D-Luciferin-Based Bioluminescence and 1,2-Dioxetane-Based Chemiluminescence Substrates for Altered Output Wavelength and Detecting Various Molecules
}

\author{
Hideo Takakura
}

check for

updates

Citation: Takakura, H. Molecular

Design of D-Luciferin-Based

Bioluminescence and

1,2-Dioxetane-Based

Chemiluminescence Substrates for

Altered Output Wavelength and

Detecting Various Molecules.

Molecules 2021, 26, 1618. https://

doi.org/10.3390/molecules26061618

Academic Editors: Akinori Kuzuya,

Roland J. Pieters, Takuya Terai,

Eylon Yavin, Alejandro Samhan-Arias and Isao Kii

Received: 31 January 2021

Accepted: 10 March 2021

Published: 15 March 2021

Publisher's Note: MDPI stays neutral with regard to jurisdictional claims in published maps and institutional affiliations.
Laboratory of Bioanalysis and Molecular Imaging, Graduate School of Pharmaceutical Sciences, Hokkaido University, Sapporo, Hokkaido 060-0812, Japan; htakakura@pharm.hokudai.ac.jp

\begin{abstract}
Optical imaging including fluorescence and luminescence is the most popular method for the in vivo imaging in mice. Luminescence imaging is considered to be superior to fluorescence imaging due to the lack of both autofluorescence and the scattering of excitation light. To date, various luciferin analogs and bioluminescence probes have been developed for deep tissue and molecular imaging. Recently, chemiluminescence probes have been developed based on a 1,2dioxetane scaffold. In this review, the accumulated findings of numerous studies and the design strategies of bioluminescence and chemiluminescence imaging reagents are summarized.
\end{abstract}

Keywords: bioluminescence; chemiluminescence; imaging; near infrared; molecular probes; design strategy

\section{Introduction}

Luminescence imaging is a powerful method for detecting biomolecules and physiological phenomena, as well as monitoring gene expression in living animals [1,2]. Luminescence imaging is advantageous because, unlike fluorescence imaging, excitation light is not required; therefore, scattered light and tissue autofluorescence is not observed. In addition, background signals in luminescence imaging can be very low, allowing for highly sensitive measurements. To date, bioluminescence in vivo imaging has been used in almost all cases of luminescence imaging of living animals. However, recently developed chemiluminescent compounds with high brightness have a great potential for chemiluminescence in vivo imaging and may be used instead of bioluminescence in some cases in the future [3].

In order to detect signals from deeper tissues in animals, it is necessary to consider the wavelength of luminescence. Visible light in the region between $400 \mathrm{~nm}$ and $600 \mathrm{~nm}$ is attenuated due to absorption by hemoglobin and oxyhemoglobin in the blood [4]. Therefore, for in vivo imaging, it is desirable to use light in the near-infrared (NIR) region, which is less absorbed by hemoglobin and oxyhemoglobin, and is less scattering by tissue. Within the NIR region, the wavelength ranges of 650-900 $\mathrm{nm}$ and 1000-1700 $\mathrm{nm}$ are called NIR-I and NIR-II, respectively [5-7]. So far, bioluminescence imaging in the NIR-I region has been studied, and in recent years, the research on NIR-II region was also reported [8]. In addition, functionalized substrates, so called probes, have been developed to detect target biomolecules and biological events in living animals. Such functionalization has been accomplished by modification of luciferin based on rational molecular design and protein engineering of luciferase utilizing bioluminescence resonance energy transfer (BRET) and split luciferase complementation [1,9]. In this review, a summary is presented of the reported molecular design of substrates emitting NIR-I bioluminescence and probes with a focus on the firefly/click beetle luciferin-luciferase system. Similar studies have been carried out in a bioluminescent system using coelenterazine as a substrate, but refer to other excellent reviews $[10,11]$. There is also a bioluminescent system with bacterial luciferinluciferase reaction, but it is not discussed in this review because it does not require the 
addition of luciferin from outside; therefore, there is no research on the molecular design of bacterial luciferin $[12,13]$. In this review, further, recent reports on chemiluminescent compounds and chemiluminescence probes are also briefly summarized.

\section{Firefly/Click Beetle Bioluminescence}

The most common bioluminescent systems for in vivo imaging are the firefly/click beetle luciferin-luciferase reactions (Scheme 1). In this reaction, luciferase catalyzes the oxidation of D-luciferin (Scheme 1, Compound 1) using oxygen molecules in the presence of adenosine triphosphate (ATP). First, ATP is used to form an adenylated luciferin, which then reacts with molecular oxygen to produce an excited state of a high energy dioxetane intermediate, oxyluciferin (Scheme 1, Compound 2). Then, the excited oxyluciferin emits light. Although various firefly/beetle luciferases are known, all luciferases consume the same D-luciferin as a substrate. The luminescence wavelength depends upon the measurement conditions and the luciferase employed. Firefly luciferase from North America results in luminescence wavelengths of $558 \mathrm{~nm}$ in neutral to weakly alkaline conditions, but $610 \mathrm{~nm}$ in weakly acidic conditions [14]. The luminescence wavelength is also affected by temperature, with higher temperatures resulting in red-shifted luminescence wavelengths [15]. Other species of luciferases, such as Brazilian luciferase and Caribbean luciferase, result in luminescence wavelengths of $538 \mathrm{~nm}$ and $613 \mathrm{~nm}$, respectively [16]. Interestingly, the luminescence wavelengths of these two luciferases are $\mathrm{pH}$-independent. Other than these variants, many mutants with altered luminescence wavelengths are known, and most of them have a longer wavelength shift than that of wild type luciferase [17-21]

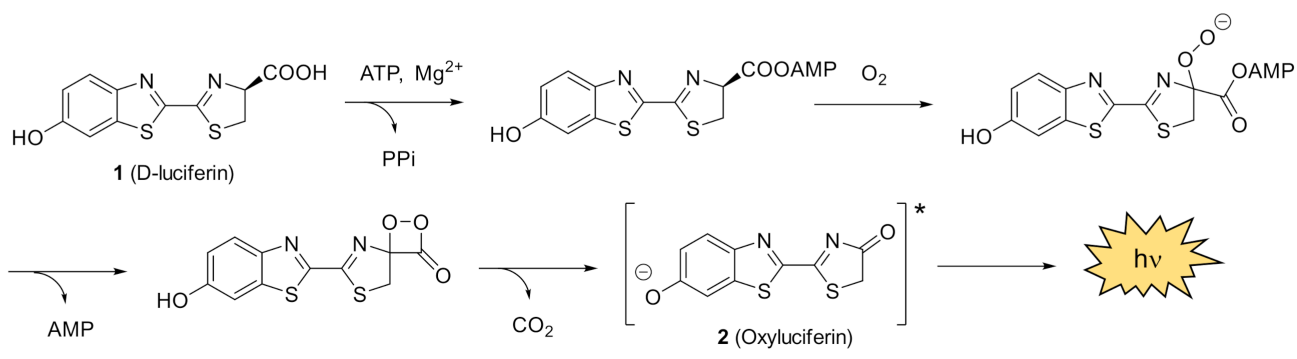

Scheme 1. The chemical reaction of firefly/click beetle bioluminescence. In the reaction, D-luciferin is adenylated by luciferase using adenosine triphosphate (ATP) followed by reaction with molecular oxygen to generate a high-energy dioxetane intermediate. Along with the decomposition of the intermediate, oxyluciferin is excited and emits light.

\section{Bioluminescent System with Longer Wavelength}

\subsection{Molecular Mechanism of Bioluminescence Color}

The molecular mechanism of the change in luminescence wavelength of firefly luciferinluciferase is still under debate due to the complex chemical and photochemical properties of oxyluciferin, the bioluminescent emitter [22-25]. For example, oxyluciferin can exist in many different tautomeric and deprotonated forms, including the keto-enol-enolate and phenol-phenolate species. In addition, the $\mathrm{pKa}$ values of the keto and phenol groups and thought to be close to each other [25]. Moreover, the photochemical properties of each structure are very sensitive to the environment [22-24]. It is now believed that the structure of the active site emitter is oxyluciferin in its keto-phenolate form and that the change in emission wavelength is due to non-specific polarity, size of the active site, and specific electrostatic interactions. According to the results of studies on the photochemical properties of oxyluciferin, the maximum emission wavelength of oxyluciferin is about $640 \mathrm{~nm}$. The currently reported variant of luciferase showing the longest wavelength is $622 \mathrm{~nm}$ in the railroad worm and $626 \mathrm{~nm}$ in the mutant, which is roughly consistent with the maximum wavelength $[16,21]$. However, these wavelengths fall short of the optical window. As long as D-luciferin is used as a substrate, it will be difficult to find variants or mutants with longer luminescence wavelengths. 


\subsection{Modification of Luciferase}

In order to develop a bioluminescent system with luminescence wavelengths in the optical window, the modification of luciferase with fluorescent dyes that emit NIR-I light, such as AlexaFluor690 or AlexaFluor750, has been attempted [26]. However, since luciferase is chemically conjugated with the fluorescent dyes outside the cell, it is difficult to introduce them into the cell after conjugation. Another approach is to create a fusion protein that combines a fluorescent protein that emits NIR-I light with a luciferase via protein engineering [27]. In this case, it is possible to introduce the gene into the cell, making it possible to apply the fusion protein to culture cells or animals. To date, there have been reports on the development of fusion proteins that are composed of red-emitting fluorescent proteins and firefly luciferase; however, there have been no reports using NIR-I-emitting fluorescent proteins [28-30]. This is absence in the literature may indicate that NIR-I fluorescent protein has not yet been identified as a suitable BRET acceptor for firefly luciferase.

\subsection{Development of D-Luciferin Analogs with Longer Wavelengths Based on Molecular Design from Substrate Specificity}

Bioluminescent systems with longer luminescence wavelengths have been developed by structurally modifying the substrate. Early studies more than 50 years ago focused on the substrate specificity of D-luciferin for luciferase [31-33]. In these studies, it was discovered that the thiazoline ring of the original structure should be conserved for emitting bioluminescence, whereas the aromatic ring and its substituents could be modified, with the requirement that a functional group with high electron density be placed at the $6^{\prime}$ position (Figure 1). These empirical findings became an important design guideline for the development of novel substrates for luciferase. In early studies, aminoluciferin (AL) (Figure 2, Compound 3), an amino-substituted form of D-luciferin, was reported as a substrate with a longer luminescence peak than D-luciferin; the luminescence spectrum had a maximum peak of $596 \mathrm{~nm}$, was $\mathrm{pH}$-independent, and exhibited a luminescence activity superior to that of other substrates [34]. Since 2000, bioluminescence has been attracting attention as a detection method for assay systems and an imaging method for living animals due to the high sensitivity of the measurement. Consequently, luminescent substrates have been actively developed. Among the studies, the original substrates D-luciferin and AL became important platforms for substrate modification.

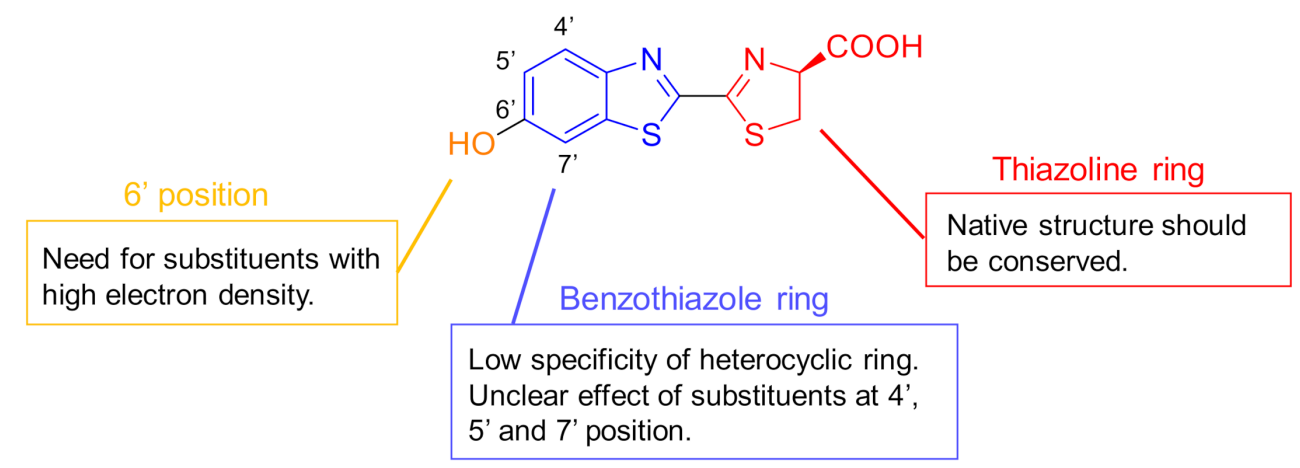

Figure 1. The substrate specificity for luciferase to emit light.

First, substrates with modification at the $6^{\prime}$ position were described (Figure 2). As mentioned above, a functional group with high electron density is required at the $6^{\prime}$ position to emit bioluminescence. If the hydroxy group is etherified or esterified, the electron density of the functional group at the $6^{\prime}$ position decreases and no bioluminescence is observed. On the other hand, $\mathrm{N}$-alkylation of AL at the $6^{\prime}$ position does not decrease the electron density; therefore, substrates that modified the amino group of AL at the $6^{\prime}$ position have been developed. As in the case of fluorescent dyes containing amino groups, such as rhodamine, 
alkylation of the amino group of AL was reported to shift the luminescence wavelength up to $\sim 620 \mathrm{~nm}$ (Compound 4, 5, 7) [35-37]. However, depending on the functional group introduced, the wavelength can be as short as $560 \mathrm{~nm}$, suggesting that other factors are also involved in the luminescence wavelength (Compound 6, 8) [37]. AL with cycloalkyl groups showed a slightly longer wavelength shift to $\sim 607 \mathrm{~nm}$ than AL (Compound 9-11) [38]. Since it is known that the fluorescence wavelength of rhodamine can be red-shifted by introducing an alkyl groups through a ring fusion rather than alkyl chain groups, substrates based on the same molecular design were also developed (Compound 12-23) [35,39]. Among them, Compound 23 showed the longest luminescence wavelength (642 nm). In addition, substrates with cyclic amino groups were also developed (Compound 24-31) [37]. These substrates showed a long wavelength shift of $\sim 612 \mathrm{~nm}$, which is comparable to that of the substrates with alkyl chain groups (Compound 4,5 ). Normally, substitution at the $6^{\prime}$ position with an amide group results in loss of bioluminescence activity of AL due to a decrease in electron density at the $6^{\prime}$ position, but the substrate with a dimethylurea group (Compound 32) exhibited luminescence and showed a luminescence wavelength of $594 \mathrm{~nm}$, which is comparable to AL [37].

Next, studies focusing on the modification of heterocycles and heteroatoms of heterocycles were described (Figure 2). In early studies, bioluminescence was reported using substrates with quinoline and naphthalene rings instead of benzothiazole rings, exhibiting a red shift of $608 \mathrm{~nm}$ for a quinoline ring and a blue shift of $524 \mathrm{~nm}$ for a naphthalene ring (Compound 33, 34) [40]. Quinoline- and naphthalene-containing substrates were also developed with amino groups at the $7^{\prime}$ position, showing luminescence wavelengths of $570-601 \mathrm{~nm}$ in the quinoline ring and 559-564 $\mathrm{nm}$ in the naphthalene ring (Compound 35-40) [41]. A substrate comprising a coumarin ring with amino groups at the $7^{\prime}$ position showed an even shorter luminescence wavelength from 500 to $526 \mathrm{~nm}$ (Compound 41-43) [41]. Further, substrates with a benzimidazole ring instead of the benzothiazole ring or imidazoline ring instead of the thiazole ring were synthesized (Compound 44-46) [42] Compound 44 showed biphasic luminescence wavelengths with the peak tops at $460 \mathrm{~nm}$ and $578 \mathrm{~nm}$, likely due to tautomerism of the emitter. Replacement of the sulfur atom in the thiazoline ring of D-luciferin and AL with carbon or selenium resulted in luminescence wavelengths of $547 \mathrm{~nm}$ and $600 \mathrm{~nm}$, respectively (Compound 47, 48) [43,44]. Substitution of pyridone ring instead of the benzothiazole ring showed a luminescence wavelength of $570 \mathrm{~nm}$ or $530 \mathrm{~nm}$ (Compound 49, 50) [45].

D-luciferin analogs with varied substituents at the $4^{\prime}, 5^{\prime}$, and $7^{\prime}$ positions were also developed (Figure 2). The substrates with a halogen at the $4^{\prime}, 5^{\prime}$, and $7^{\prime}$ positions tended to shift to longer wavelengths than D-luciferin (Compound 51-56) [14,46,47]. Among them, the substrate with bromine at the $4^{\prime}$ position (Compound 55) showed the longest luminescence wavelength of $630 \mathrm{~nm}$. The substrates with allyl, hydroxymethyl, or alkynyl groups at the $5^{\prime}$ or $7^{\prime}$ positions showed longer luminescence wavelengths up to $617 \mathrm{~nm}$ (Compound 57-62) [14,48,49]. When a bulkier functional group was introduced into the $7^{\prime}$ position of D-luciferin, the luminescence wavelengths were almost identical to D-luciferin (Compound 63-65), while the substitution at the $4^{\prime}$ position resulted in a longer wavelength shift to $612 \mathrm{~nm}$ (Compound 66) [50]. 


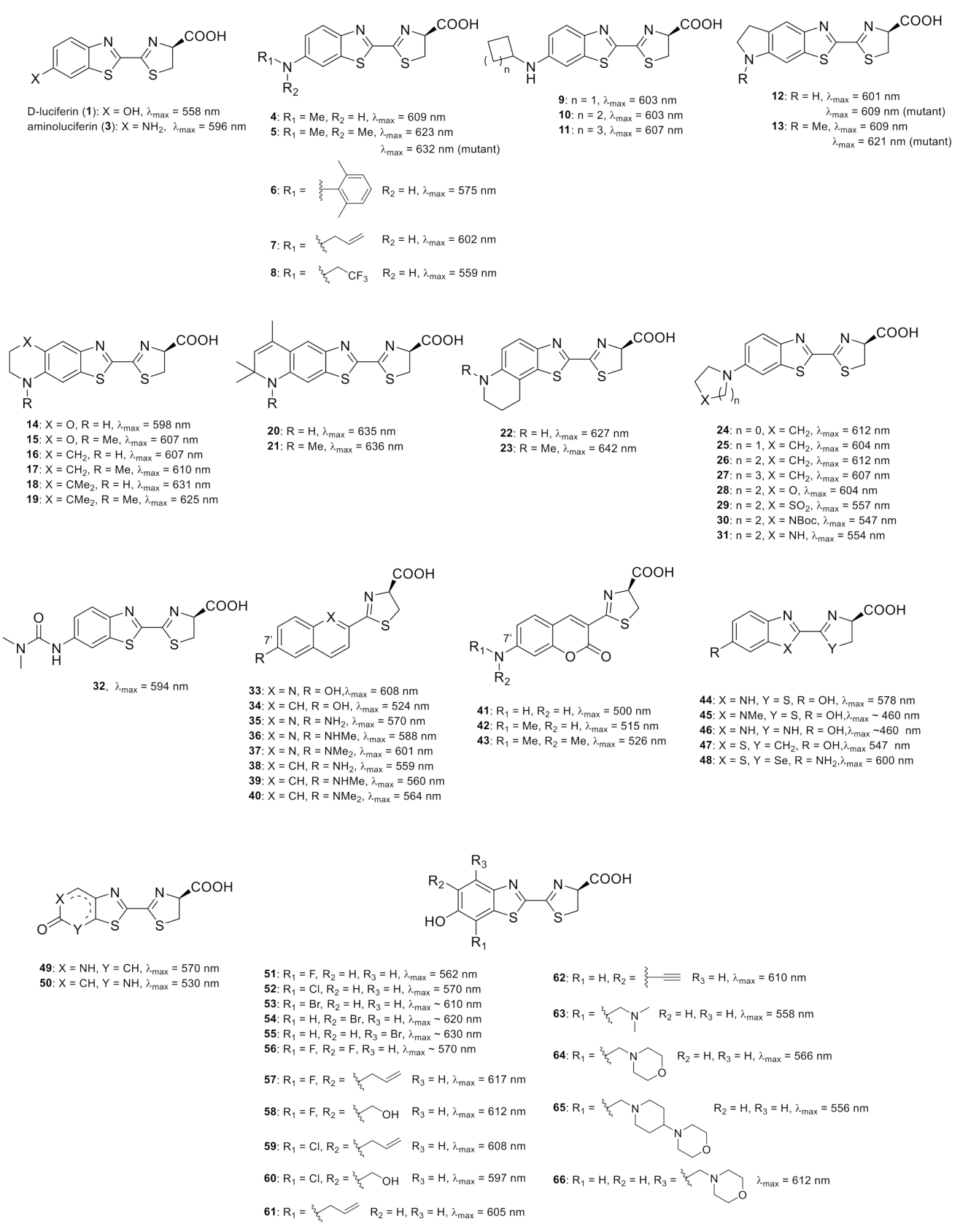

Figure 2. Chemical structures of substrates which were designed using substrate specificity.

\subsection{Development of D-Luciferin Analogs with Expanded $\pi$ Conjugation System}

Substrates that were developed based on the initial findings on the substrate specificity of luciferase did not successfully exhibit luminescence peak wavelengths in the optical window. Thus, for the development of NIR-I emitting substrates, a different design strategy was attempted. Maki et al. found that substrates with a double bond inserted between the aromatic ring and the thiazoline ring of D-luciferin and AL also exhibits luminescence, and that this type of luminescent substrate, as in the case of fluorescent dyes, showed a narrowing of the highest occupied molecular orbital (HOMO)-lowest unoccupied molecular orbital (LUMO) gap due to the elongation of the $\pi$-conjugated system, leading to a red-shift of the luminescence wavelength. This research resulted in the development of numerous substrates with elongated $\pi$-conjugated systems (Figure 3 ). Maki and co-workers synthesized substrates consisting of a thiazoline ring directly bonded to either a phenol or $\mathrm{N}, \mathrm{N}$-dimethylaniline or connected via a double bond linker (Compound 67-70, 72, 73) [51]. In the case of the same heterocyclic structure, substrates with a dimethylamino group 
showed a longer luminescence wavelength of about 15-35 nm compared to those with a hydroxy group. In addition, the insertion of a double bond between the two hetrocyclic ring structures led to a longer wavelength shift of about $100 \mathrm{~nm}$ per bond. In particular, Compound 73, named AkaLumine, was found to be a substrate with a maximum luminescence wavelength in the optical window. After that, based on the structure of AkaLumine, various substrates were developed. The introduction of an allyl group at the $7^{\prime}$ position in AkaLumine was expected to cause a long wavelength shift, as in the case of D-luciferin (Compound 71, 74) [52]. As a result, a longer wavelength shift of about 10-15 nm was observed compared to the unsubstituted substrates. AkaLumine did not exhibit good solubility in water, so a more water-soluble substrate was developed by introducing a nitrogen atom into the benzene ring (Compound 75-77) [53]. The luminescence wavelength changed depending on the position of nitrogen $(620-675 \mathrm{~nm})$. Since the luminescence wavelength of AL was changed by the introduction of a cyclic amine groups and ring-fused alkyl amino groups, the same molecular design was applied to AkaLumine (Compound 78-87) [54,55]. Among the developed substrates, Compound $\mathbf{8 7}$ had the longest luminescence of 690 $\mathrm{nm}$. In addition to phenol and $N, N$-dimethylaniline, additional substrates were prepared bearing other heterocyclic rings, including naphthalene rings and benzothiazole rings connected via double bond linkers (Compound 88-90) [51,52,56]. All of these substrates were shifted to longer wavelengths by about $100 \mathrm{~nm}$ compared to the analogous substrates lacking the double bond linker.

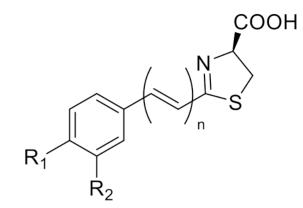

66: $n=0, R_{1}=O H, R_{2}=H, \lambda_{\max }=440 \mathrm{~nm}$ $67: n=0, R_{1}=\mathrm{NMe}_{2}, \mathrm{R}_{2}=\mathrm{H}, \lambda_{\max }=445 \mathrm{~nm}$ 68: $n=1, R_{1}=O H, R_{2}=H, \lambda_{\max }=530 \mathrm{~nm}$ 69: $n=1, R_{1}=\mathrm{NMe}_{2}, \mathrm{R}_{2}=\mathrm{H}, \lambda_{\text {max }}=560 \mathrm{~nm}$ 70: $n=1, R_{1}=\mathrm{NMe}_{2}, \mathrm{R}_{2}=\xi \quad \lambda_{\max }=575 \mathrm{~nm}$

$71: n=2, R_{1}=O H, R_{2}=H, \lambda_{\max }=640 \mathrm{~nm}$ AkaLumine (72): $n=2, R_{1}=\mathrm{NMe}_{2}, \mathrm{R}_{2}=\mathrm{H}, \lambda_{\max }=675 \mathrm{~nm}$ $73: n=2, R_{1}=\mathrm{NMe}_{2}, \mathrm{R}_{2}=\xi \quad \lambda_{\max }=685 \mathrm{~nm}$

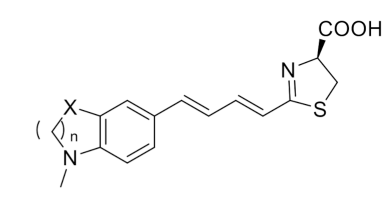
81: $n=1, X=\mathrm{CH}_{2}, \lambda_{\max }=684 \mathrm{~nm}$
82: $\mathrm{n}=2, \mathrm{X}=\mathrm{CH}_{2}, \lambda_{\max }=683 \mathrm{~nm}$ 83: $\mathrm{n}=2, \mathrm{X}=\mathrm{CMe}_{2}, \lambda_{\max }=684 \mathrm{~nm}$ 84: $n=2, X=O, \lambda_{\text {max }}=680 \mathrm{~nm}$

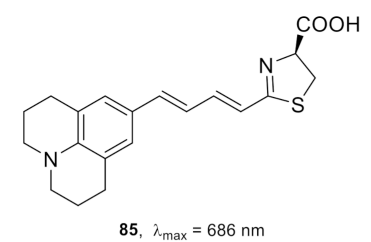

85, $\lambda_{\max }=686 \mathrm{~nm}$

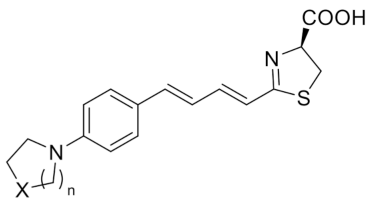
$77: \mathrm{n}=1, \mathrm{X}=\mathrm{CH}_{2}, \lambda_{\max }=667 \mathrm{~nm}$
$78: \mathrm{n}=2, \mathrm{X}=\mathrm{CH}_{2}, \lambda_{\max }=667 \mathrm{~nm}$ 79: $\mathrm{n}=3, \mathrm{X}=\mathrm{CH}_{2}, \lambda_{\max }=656 \mathrm{~nm}$ 80: $n=2, X=O, \lambda_{\max }=665 \mathrm{~nm}$

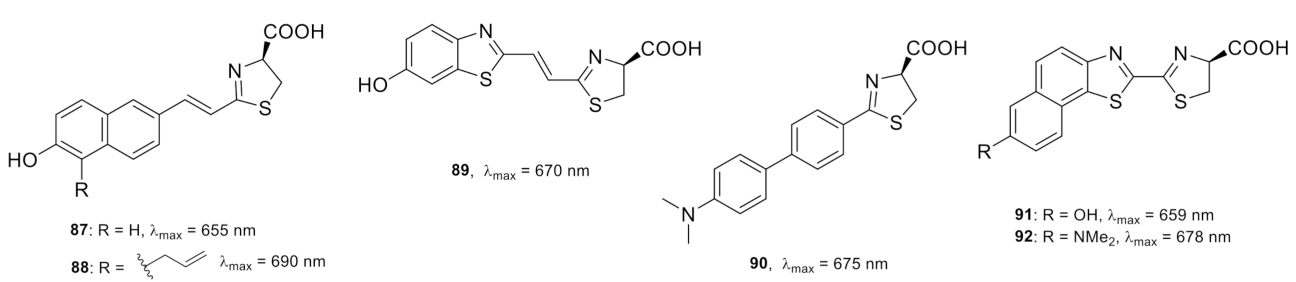

Figure 3. Chemical structures of substrates with elongated $\pi$-conjugated systems.

Other substrates with heterocyclic rings, such as biphenyl and naphtho[2,1]thiazole rings, were developed (Compound 91-93) [57,58]. All of these substrates showed luminescence wavelengths in the NIR-I region of $659-678 \mathrm{~nm}$. Substrates with longer luminescence wavelengths utilizing bioluminescence resonance energy transfer (BRET) were also reported (Compound 94-97) (Figure 4) [59]. Fluorescent dyes with a wavelength in the NIR-I region, such as Cy5, BODIPY 650/665, SiR700, Cy7, etc., were attached to the amino group 
of AL via a linker. In these substrates, BRET from the AL to the NIR-I fluorescent dye efficiently occurred and showed luminescence wavelengths in the NIR-I region.

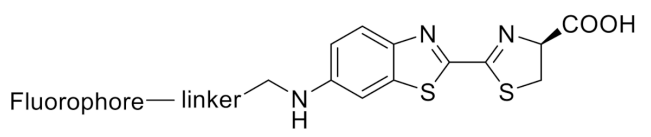

93: Fluorophore $=\mathrm{Cy} 5, \lambda_{\max } \sim 670 \mathrm{~nm}$

94: Fluorophore $=$ BODIPY $650 / 665, \lambda_{\max } \sim 670 \mathrm{~nm}$

95: Fluorophore $=\mathrm{SiR} 700, \lambda_{\max } \sim 720 \mathrm{~nm}$

96: Fluorophore $=$ Cy7, $\lambda_{\max } \sim 800 \mathrm{~nm}$
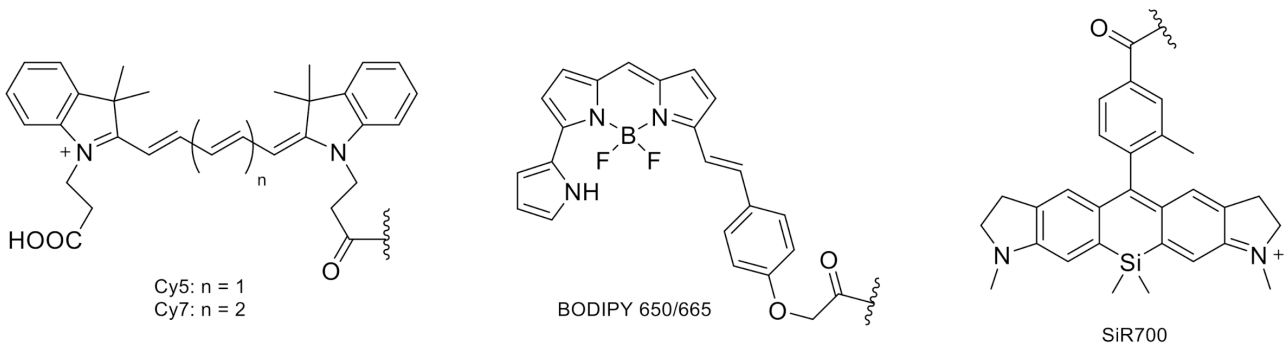

Figure 4. Chemical structures of substrates based on bioluminescence resonance energy transfer (BRET).

\subsection{Mutant of Luciferase for Synthetic Substrates}

Although various types of NIR-I light-emitting substrates for luciferase have been developed, almost none of them emit brighter light than D-luciferin; indeed, many of them emit less than $1 \%$, and in the worst case, some of them emit less than $0.01 \%$ [51]. The main reason for this is thought to be that the adenylation reaction, the first step in the bioluminescence reaction, is very slow. For example, a substrate with a pyrroline ring instead of a thiazole ring (Compound 47 ) shows only about $0.5 \%$ luminescence compared to D-luciferin. However, when the adenylated substrate reacted with luciferase, the luminescence intensity was drastically improved to about $23 \%$ compared to adenylated D-luciferin [44]. Unfortunately, adenylated substrates could not be used as substrates because they do not readily penetrate the cell membrane due to the negatively charged phosphate group, which renders them unstable. Therefore, it would be advantageous to instead increase the reaction rate of the adenylation step, thereby improving the light output. To that end, research has been conducted to find luciferases with optimal active sites for specific substrates through the large-scale screening of mutation. The first attempt was to screen for optimal luciferases for AL derivatives 12 and 13; as a result, mutants for Compound 12 and 13 with improved luminescence were found [60]. In several similar studies, mutants showing longer wavelengths also have been discovered. For example, mutants for Compound 90 and 92 emit red-shifted bioluminescence with peak wavelengths from $670 \mathrm{~nm}$ to $706 \mathrm{~nm}$ and $659 \mathrm{~nm}$ to $758 \mathrm{~nm}$, respectively, compared to the native luciferase [56,58]. The most successful example of the mutation studies is probably Akaluc against Akalumine, reported by Miyawaki et al. Akaluc has mutations of 28 amino acids and is more than 1000 times brighter than the native luciferase [61]. Using the system with AkaLumine and Akaluc, Miyawaki et al. observed luminescence from a single cell in a live mouse and a brain of freely moving mouse. They also successfully imaged bioluminescence from the brain of a much larger animal, the marmoset. This system is one of the most sensitive luminescence systems available today for in vivo imaging. 


\section{Bioluminescence Probe}

\subsection{Strategy for the Development of Bioluminescence Probes}

The substrates described above are mainly used for the imaging of luciferase as a reporter enzyme, for example, to monitor gene expression, promoter activity, and cell tracking. On the other hand, bioluminescence probes, so-called bioluminogenic probes or activatable probes, have been developed to detect specific molecules or enzyme activities by modifying the substrate structure. Bioluminescence probes do not emit light when reacting with luciferase or do not function as a luminescent substrate. However, when the bioluminescence probe reacts with the target molecules, the probe changes its structure and becomes a luminescent substrate, finally emitting light in the presence of luciferase. Two rational strategies for the molecular design of bioluminescence probes have been utilized so far: one is the caged luciferin strategy and the other is the strategy utilizing bioluminescence quenching by electron transfer in the excited state (Figure 5). The caged luciferin strategy focuses on the functional groups of the substrate required for bioluminescence. Bioluminescent activity is initially masked by a reaction moiety of the target molecule; but reaction with the target molecule causes deprotection of the reaction site and subsequent release or generation of D-luciferin or AL, resulting in bioluminescence. For example, the $6^{\prime}$-O-ether and $6^{\prime}$-O-ester derivatives of D-luciferin are known to be non-luminescent substrates and are actually used as inhibitors. Therefore, when a reactive moiety for the target molecule is attached to D-luciferin at the $6^{\prime}$ position via an oxygen atom, this substrate does not emit light. However, when the target molecule reacts with the reactive moiety, the substrate is converted to D-luciferin and light is emitted. Using this strategy, it is possible to detect and quantify the target molecule by luminescence. Similarly, since amidation of AL at the $6^{\prime}$ position results in the loss of its bioluminescent activity, the $6^{\prime}-\mathrm{N}$-amide has been used in the reaction site for the molecular design of caged luciferin. Another masking site is the carboxylic acid at position 4 of the thiazoline ring. Adenylation of the carboxylic acid is essential for the bioluminescence reaction, but in amide and ester forms, the adenylation reaction does not proceed anymore and the luminescence activity is lost. Therefore, 4-ester and 4-amide derivatives of D-luciferin have been used for caged luciferin-type bioluminescence probes. These molecular designs can be applied to target molecules that cause a cleavage reaction for a specific structure. Using the caged luciferin strategy, many bioluminescence probes, such as detecting enzyme activity, small molecules, and metals, have been developed so far, as will be shown in the next section. The other strategy for developing bioluminescence probes relies upon photoinduced electron transfer (PeT), which has been used previously to develop fluorescence probes [62-64]: Bioluminescence can be quenched by the electron transfer from the donor moiety in the vicinity to the substrate (luminophore) in the excited state, although the excitation process is different (i.e., by excitation light for fluorescence and chemical reaction for bioluminescence). This phenomenon is called bioluminescent-enzyme induced electron transfer (BioLeT) [65]. The electron transfer is controlled by the electron density of the electron donor moiety, so the bioluminescence can be also controlled by changing the electron density. The strategy of using caged luciferin is applied to target molecules that cause cleavage reactions, while BioLeT is applied to target molecules that change the electron density of the reaction moiety. 
(a)

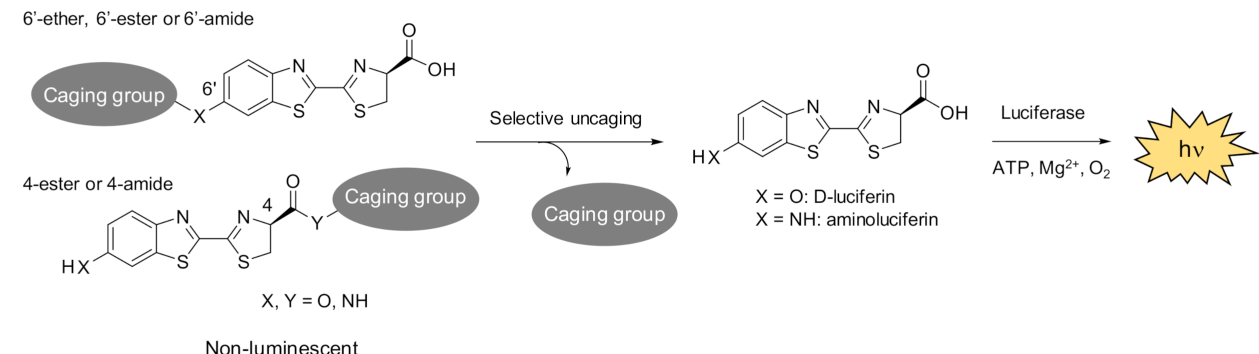

(b)
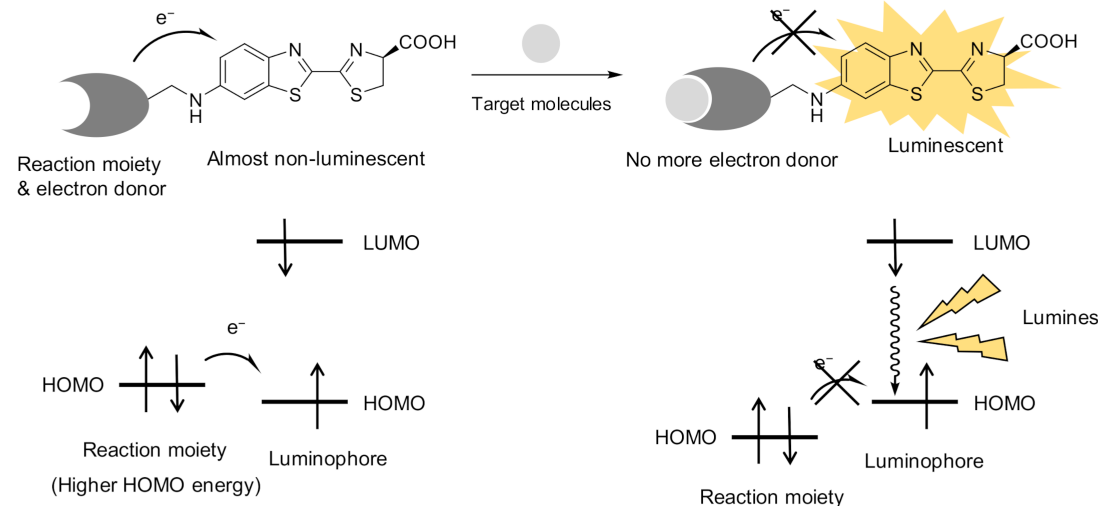

No more electron donor

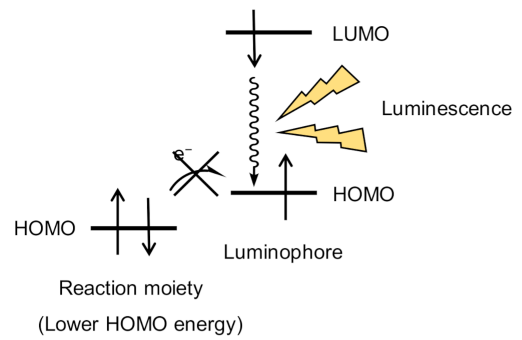

Figure 5. Molecular designs for the development of bioluminescence probes. The design strategy of (a) caged luciferin and (b) bioluminescent-enzyme induced electron transfer (BioLeT). The rate of electron transfer is strongly dependent on the highest occupied molecular orbital (HOMO) energy level of the electron donor. If the HOMO energy level of the electron donor is enough high, after luciferin derivatives react with luciferase, the electron transfer easily occurs from the electron donor to the excited luminophore. In this case, the excited electron cannot return to the HOMO of the luminophore, resulting in loss of bioluminescence. When the HOMO energy level of the electron donor becomes lower after reaction with target molecules, the electron transfer does not occur anymore, and bioluminescence should be restored.

\subsection{Development of Bioluminescence Probes Based on a Caged Luciferin Strategy}

The first bioluminescence probe was developed to detect the activity of $\beta$-galactosidase using a caged luciferin (Compound 98) [66]. A $\beta$-galactosyl group was attached to D-luciferin at the $6^{\prime}$ position, resulting in loss of luminescence activity. However, in the presence of $\beta$-galactosidase, the galactosyl group is cleaved to produce D-luciferin, and the enzyme activity can be detected by bioluminescence. The strategy of using a caged luciferin has been employed to develop many probes for detecting enzyme activity (Figure 6). For example, detection of phosphatase (Compound 99-101) [67,68], $\beta$-lactamase (Compound 102) [69], monoamine oxidase (MAO) (Compound 103, 104) [70], fatty acid amide hydrolase (Compound 105) [71], nitroreductase (Compound 106-109) [72-75], P450 (Compound 110) [76], tyrosinase (Compound 111, 112) [77,78], $\gamma$-glutamyl transferase (Compound 113, 114) [79,80], glutathione S-transferase (GST) (Compound 115-121) [81], and pantetheinase (Compound 122) [82], etc., are all based primarily on the 6 '-O-ether type of D-luciferin or the $6^{\prime}-\mathrm{N}$-amide type of AL. In addition, the $6^{\prime}$-N-amide type of AL has been used for detecting endopeptidases, such as, $\alpha$-chymotrypsin (Compound 123) [83], caspase $3 / 7$ (Compound 124) [84], furin (Compound 125) [85], and fibroblast activation protein- $\alpha$ (Compound 126) [86]. In addition to enzymes, other targeted biomolecules include reactive oxygen species, such as hydrogen peroxide (Compound 127, 128) [87,88], hypochlorite (Compound 129, 130) [89,90], and peroxynitrite (Compound 131) [91], active sulfur molecular species, such as hydrogen sulfide (Compound 132-134) [92,93] and polysulfide (Compound 135) [94], and biothiols (Compound 136-139) [95-97] (Figure 7). Further, bioluminescence probes for ions, such as copper (Compound 140, 141) [98,99], 
palladium (Compound 142, 143) [100], iron (Compound 144) [101], and fluorine (Compound 145, 146) [102], have also been reported (Figure 8). Bioluminescence probes have also been developed for dual target molecules (Compound 147, 148) [103] (Figure 9): For example, Compound 147 and 148 react with hydrogen peroxide and caspase 8 to release a luciferin precursor and D-cysteine, respectively. Since the two molecules react with each other under physiological conditions to produce D-luciferin, luminescence is generated only when both hydrogen peroxide and caspase 8 are present. These various examples illustrate that bioluminescence probes have been successfully used for a variety of target molecules using the caged luciferin strategy.
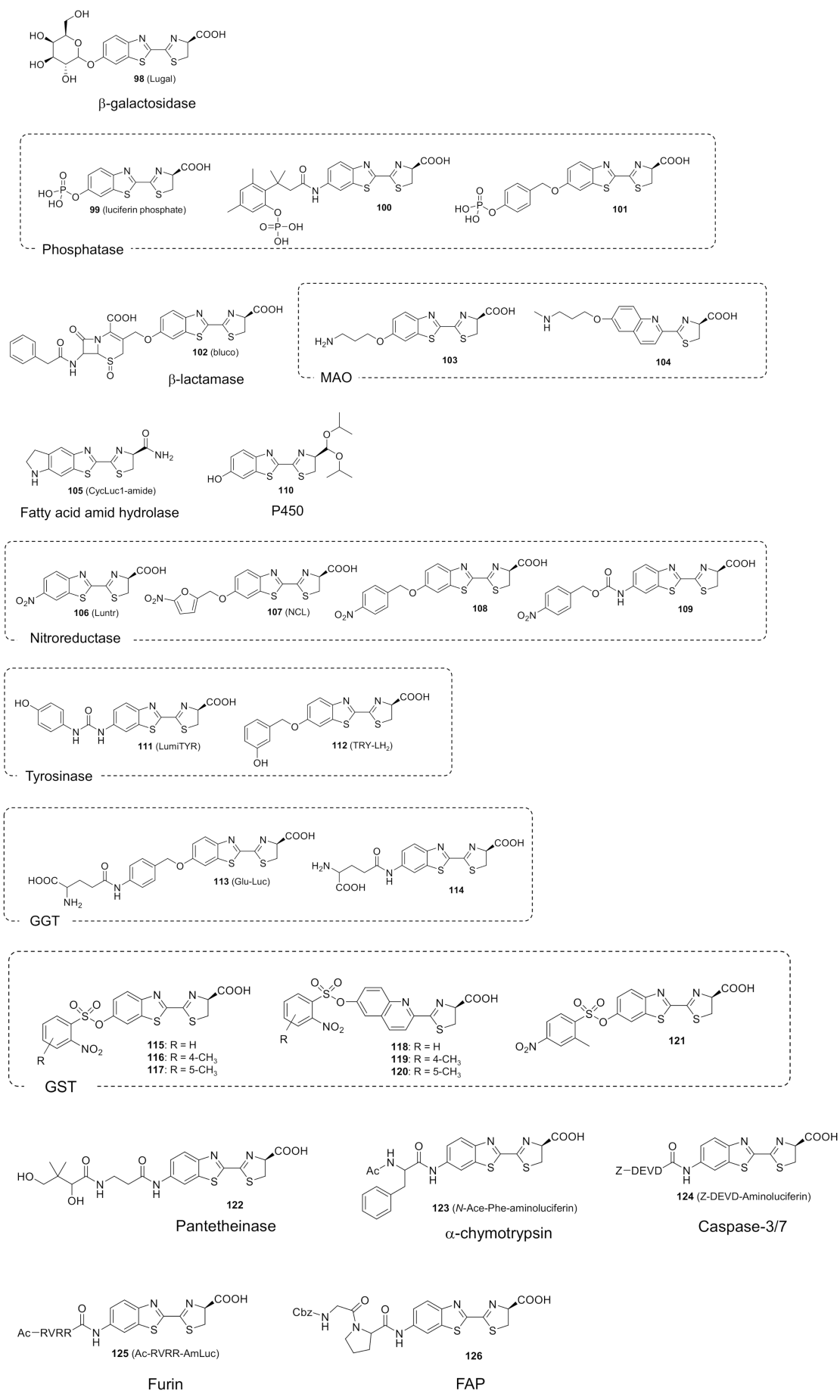

Figure 6. Chemical structures of bioluminescence probes for the detection of enzyme activity. 

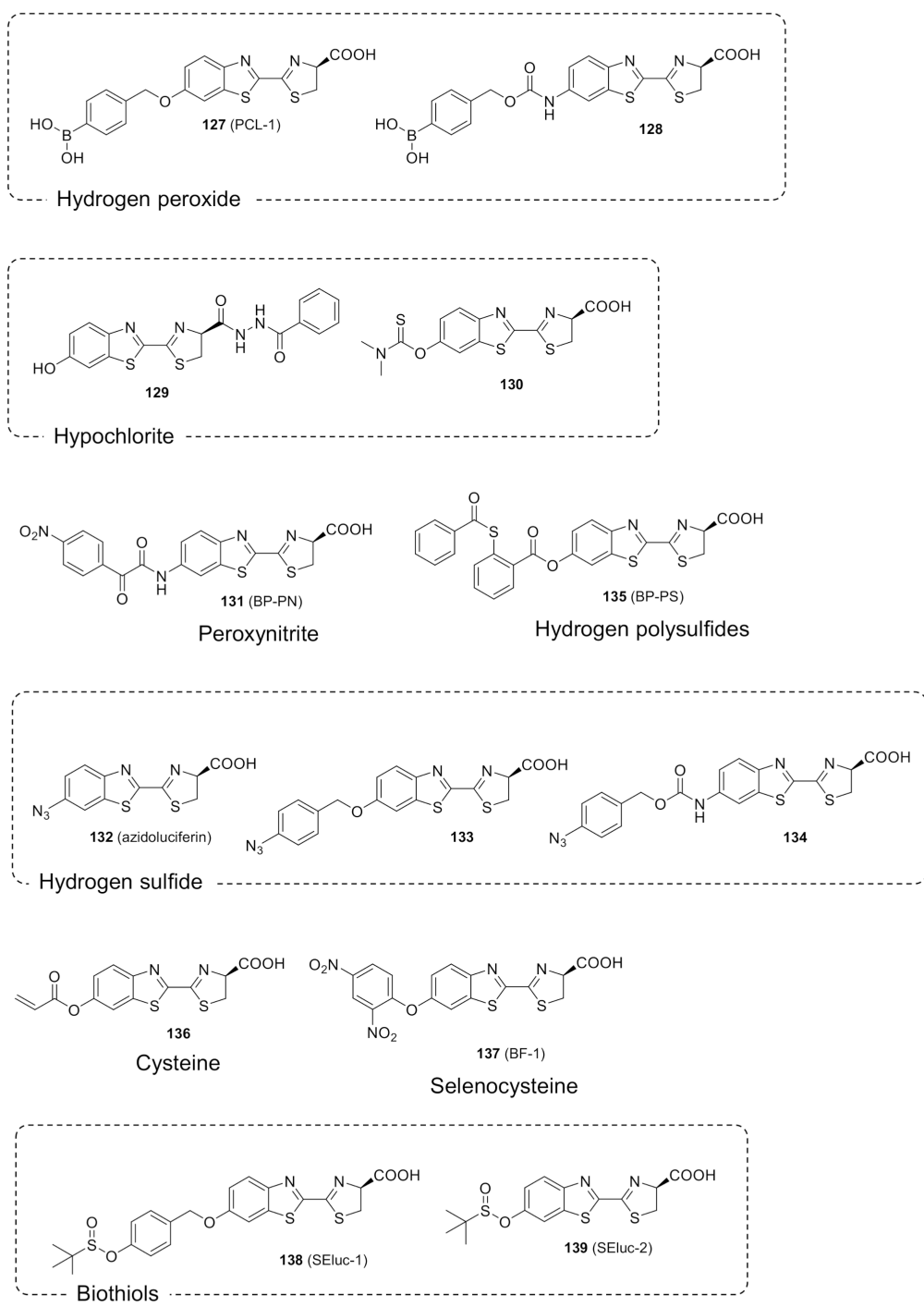

Figure 7. Chemical structures of bioluminescence probes for small molecules.

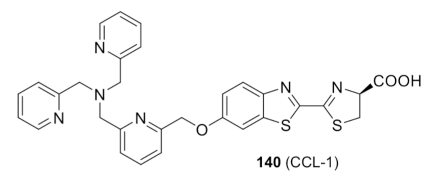

$\mathrm{Cu}^{+}$

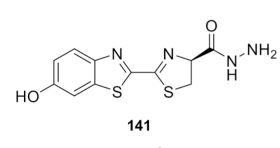

$\mathrm{Cu}^{2+}$
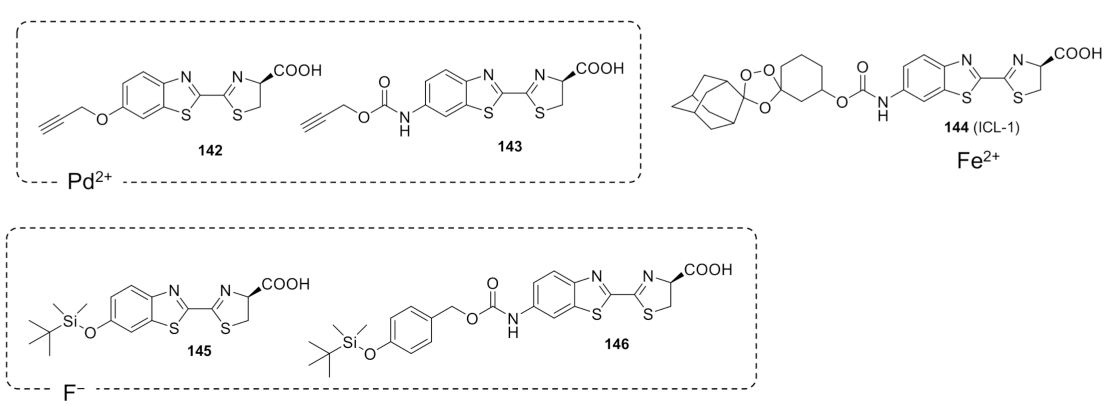

Figure 8. Chemical structures of bioluminescence probes for ions. 


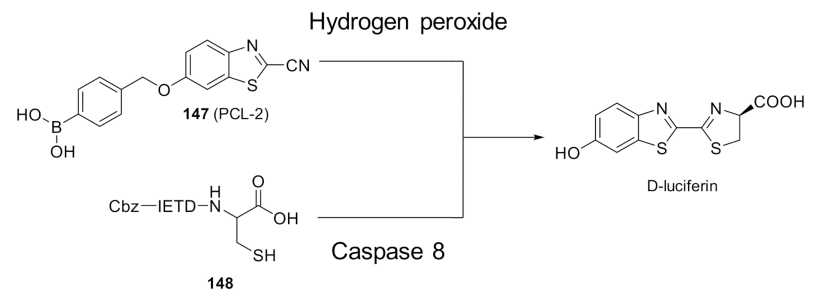

Figure 9. Chemical structures of bioluminescence probe for dual analytes.

The caged luciferin strategy has been applied not only to the detection of biomolecules but also the environment, external stimuli, chemical reactions and biological events (Figure 10). For example, the bioluminescence probes have been reported whose structures are altered by hypoxia in the cell (Compound 149) [104] or by light (Compound 150-152) [105]. In addition, bioluminescence probes can respond to the Staudinger ligation (Compound 153) [106]. In Staudinger ligation, a trivalent phosphorus compound reacts with an azide compound to give an iminophosphorane compound, which then undergoes hydrolysis. Here, the hydrolysis reaction is designed to produce D-luciferin as a hydrolysis product. By applying the probe to cells that are taken up azide sugars, it is possible to monitor the glycome on the surface of the cell membrane which changes according to the developmental stage, cellular activation, and so on. Another bioluminescence probe that reacts with intracellular thiols to produce D-luciferin when taken up into the cell has also been developed (Compound 154) [107]. By attaching the fatty acid to the probe, the amount of fatty acid uptake can be quantified.
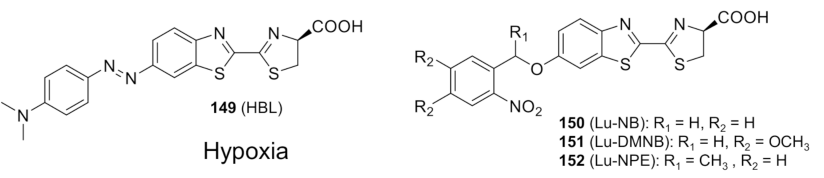

Light

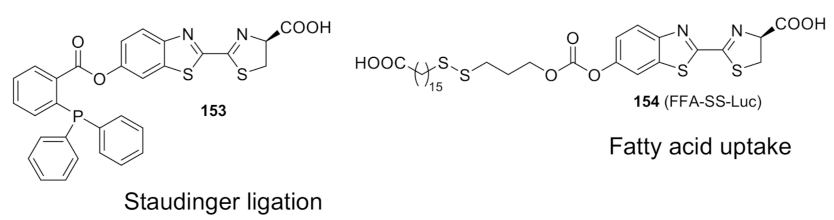

Figure 10. Chemical structures of bioluminescence probes for hypoxia, light, Staudinger ligation, and fatty acid uptake.

In the development of caged luciferin-type bioluminescence probes, it is necessary to consider whether the reaction moieties should be attached to the substrates directly or through a linker, and whether a $6^{\prime}$-O-ether type of D-luciferin or $6^{\prime}-N$-amide type of $\mathrm{AL}$ is better. The performance of bioluminescence probes with the different structures for the same target molecules have been compared in several papers. In the probes detecting the activity of nitroreductase, a nitro group functions as the reactive moiety. One study reported the development of three probes; the direct conjugate type (Compound 106), D-luciferin benzylether linker type (Compound 108), and AL benzyloxycarbonyl linker type (Compound 109) [75]. In a comparison of these three probes, Compound 108 showed the best performance as a nitroreductase probe, perhaps because of enzyme recognition. In the case of the hydrogen sulfide probe, an azido group was used as the reactive moiety. Like nitroreductase probes, the direct conjugate type (Compound 132), D-luciferin benzylether linker type (Compound 133), and AL benzyloxycarbonyl linker type (Compound 134) were compared and Compound $\mathbf{1 3 2}$ had the best reactivity for hydrogen sulfide [93]. In the biothiol probes which contained a tert-butyl sulfinyl group as the reaction moiety, the D-luciferin benzylether type (Compound 138) was more reactive than the direct conjugate type (Compound 137) [97]. In the development of palladium ion probes with a propargyl 
group as the reaction moiety, the AL oxycarbonyl linker type (Compound 143) was better than the D-luciferin ether type (Compound 142) [100]. In the fluorine ion probes whose reaction moiety is tert-butyl dimethylsilyl group, the direct conjugate type (Compound 145) was superior to an AL benzyloxycarbonyl linker (Compound 146) [102]. Thus, the optimum structure for a particular target molecule depends upon both enzyme recognition and the reactivity; therefore, it is best to optimize the reaction moiety when developing bioluminescence probes.

\subsection{Development of Bioluminescence Probes Based on the BioLeT Strategy}

Next, the development of a bioluminescence probe using BioLeT was described. As mentioned earlier, the basic concept of BioLeT is the same as that of PeT. In other words, bioluminescence can be quenched in the excited state by electron transfer from the electron donor to the emitter, although the excitation process is different. The molecular design of caged luciferin can be applied to the target molecules involved in the reaction of bond breaking, while BioLeT can target chemical reactions that cause changes in electron density (HOMO energy level). One advantage of probes based on BioLeT is that the chemical reactions in which the target molecule binds or coordinates to the reaction moiety can be applied to the molecular design of the probe, as long as the electron density of the reaction moiety changes before and after the reaction. So far, bioluminescence probes utilizing BioLeT for the detection of nitric oxide (Compound 155) and highly reactive oxygen species (hROS) (Compound 157), such as hypochlorite, peroxynitrite, and hydroxyl radical, have been developed (Figure 11) [65,108]. Compound 155 has a diaminobenzene structure whose electron density is very high, so even in the presence of luciferase, electron transfer from the diaminobenzene to the emitter occurs, resulting in loss of bioluminescence. The structure is also the reaction moiety for nitric oxide as the target molecule, and, when reacted with nitric oxide in the presence of oxygen, it is converted to a triazole structure (Compound 156). The electron density of the structure is reduced, so that electron transfer from the triazole to the emitter does not occur, thus recovering luminescence. Similarly, Compound 157 bearing an aminophenoxy moiety as a reaction moiety does not exhibit bioluminescence in the presence of luciferase because the electron density of the aminophenoxy moiety is sufficient to quench bioluminescence. The aminophenoxy moiety can react with hROS and is cleaved via an ipso-substitution reaction. Therefore, after the reaction, Compound 157 is converted to Compound 158, which has no reaction moiety with high electron density, and shows bioluminescence. Although there are only two examples of bioluminescence probes using BioLeT, it is expected that bioluminescence probes based on this design principle will be developed in the future because the same molecular design as PeT can be applied.
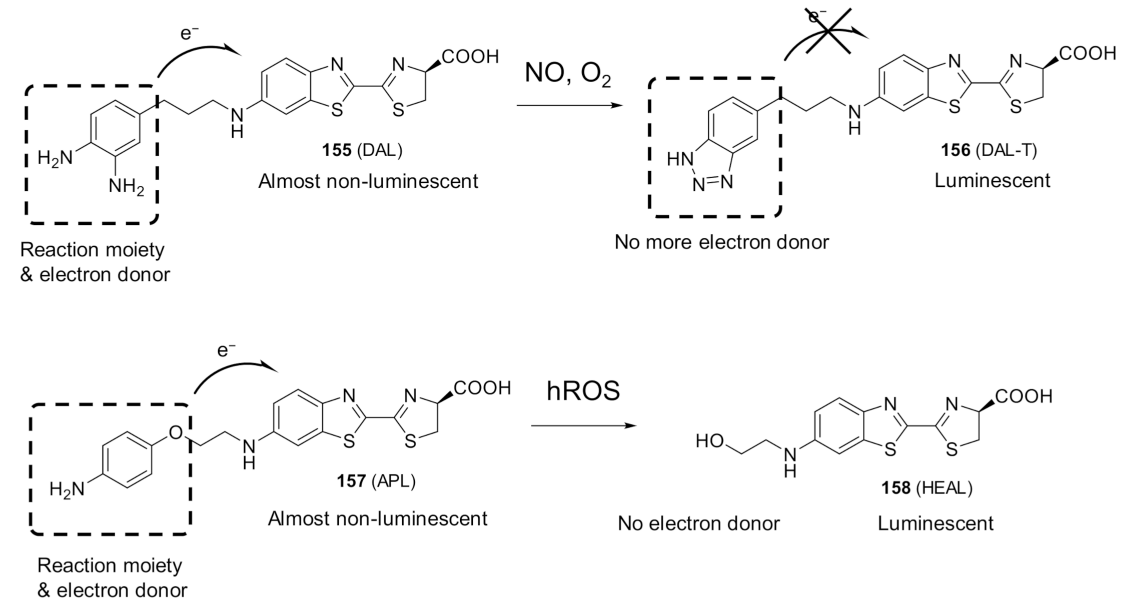

Figure 11. Chemical structures of bioluminescence probes based on bioluminescent-enzyme induced electron transfer (BioLeT). 


\section{Chemiluminescence}

Chemiluminescence, which is produced by chemical reaction in absent of enzyme/protein, is a well-known phenomenon. One of the most famous chemiluminescent compounds is luminol, which reacts with reactive oxygen species, followed by the generation of the high-energy four-membered ring peroxide, so-called 1,2-dioxetane. Since the $\mathrm{O}-\mathrm{O}$ bond has enough energy to allow the molecule to decompose thermally into an electronically excited product, the 1,2-dioxetane compound is spontaneously excited with decomposition into two carbonyl fragments, resulting in production of light. So far, chemiluminescence has been applied to detection systems in biochemical and bioimaging research $[109,110]$. However, chemiluminescence has not attracted as much attention as bioluminescence because the brightness in neutral aqueous solution is not high and the luminescence wavelength is limited due to a decreased variation in chemiluminescent compounds. Recently, Shabat et al. developed chemiluminescent compounds with high brightness in neutral aqueous solution. They used 1,2-dioxetane stabilized with an adamantane structure as a basic structure of the synthesized chemiluminescent compounds (Compound 159) (Figure 12). The compounds possess a phenol group, which upon conversion to the phenolate in the decomposition reaction is excited, resulting in generation of chemiluminescence. Shabat and co-workers developed a series of very bright chemiluminescent compounds by attaching fluorescent dyes with high fluorescence quantum yields utilizing chemiluminescence resonance energy transfer (CRET) (Compound 160, 161) (Figure 12) [111]. This molecular design worked well, and the excitation energy before relaxation was efficiently transferred to the fluorescent dyes, resulting in bright chemiluminescence. However, they found that the compounds based on the concept of CRET were unstable to light due to electron transfer from the fluorescent dyes absorbing light. To develop other chemiluminescent compounds with high brightness, they focused on the chemiluminescence quantum yields which consist of the reaction quantum yield, singlet excitation quantum yield and fluorescence quantum yield of the emitter. To improve the fluorescence quantum yield of the emitter, they synthesized 1,2-dioxetanes containing an acrylic group (Compound 162-165) (Figure 12) [112]. With this approach, they successfully developed chemiluminescent compounds with high brightness in aqueous solution. In recent years, there has been a great deal of research using such compounds. For example, chemiluminescent compounds with longer luminescence wavelengths were prepared by extending the $\pi$-conjugated system (Compound 166, 167), the half-life time of the 1,2-dioxetane compounds, which depends on structures (2-1100 s), was investigated, and the chemiluminescence probes have been synthesized [113,114]. The chemiluminescence reaction of 1,2-dioxetanes proceeds from its phenolate form, and this reaction can be inhibited by introducing a protecting group at the site. Therefore, the strategy of caged luciferin can be applied to the development of chemiluminescence probes. Although the chemiluminescent compounds have only been developed for a short time, to date various chemiluminescence probes have been reported, including chemiluminescence probes for detecting the activities of enzymes, such as $\beta$-galactosidase (Compound 168-171) [112,115], phosphatase (Compound 172) [112], nitroreductase (Compound 173) [116], cathepsin B (Compound 174) [117], and nicotinamide adenine dinucleotide/nicotinamide adenine dinucleotide phosphate (NADH/NADPH) quinone oxidoreductase-1 (NQO1) (Compound 175) (Figure 13) [118]. In addition, chemiluminescence probes have been designed to detect small molecules, such as hydrogen peroxide (Compound 176, 177) [112,113], glutathione (GSH) (Compound 178) [112], peroxynitrite (Compound 179) [119], cysteine (Compound 180) [120], and formaldehyde (Compound 181, 182) (Figure 13) [121]. Further, chemiluminescence probes for bacteria have been developed utilizing reaction moieties for specific bacterial enzymes (Compound 183, 184) (Figure 13) [122]. Several probes have been shown to be more sensitive than fluorescence probes and have been applied to in vivo imaging. Various studies are expected to be conducted in the future. 

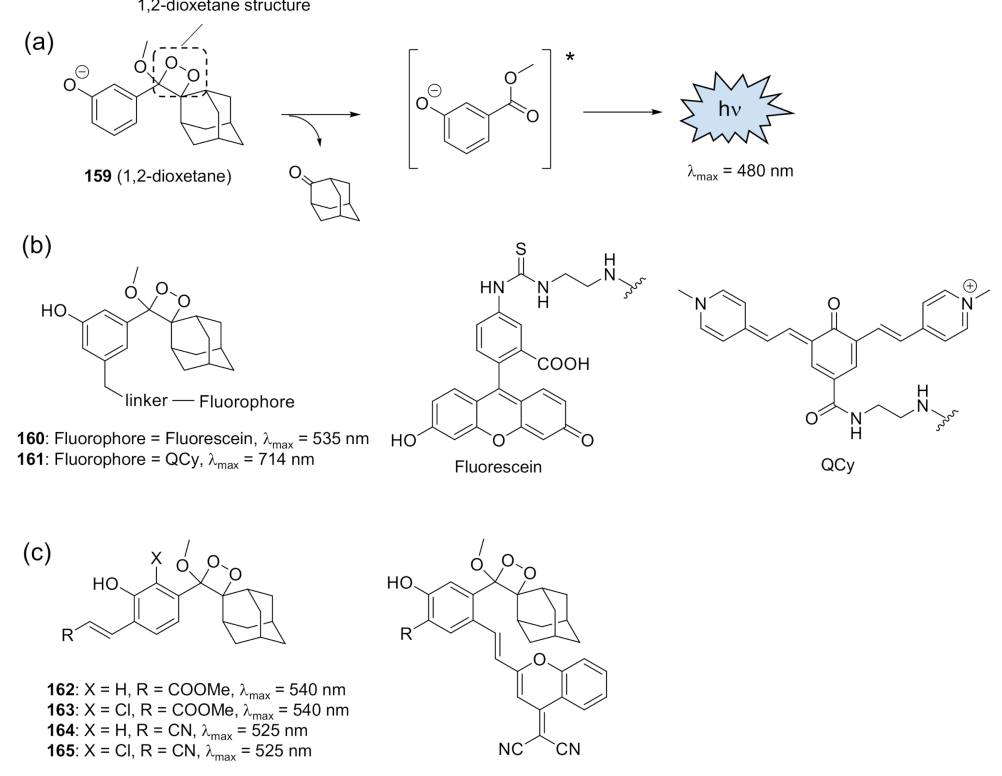

166: $\mathrm{R}=\mathrm{H}, \lambda_{\max }=660 \mathrm{~nm}$

167: $\mathrm{R}=\mathrm{O}_{\mathrm{OH}}^{\mathrm{OH}} \quad \lambda_{\max }=690 \mathrm{~nm}$

Figure 12. (a) Chemiluminescence reaction of 1,2-dioxetane. (b) Chemical structures of chemiluminescent compounds conjugated with fluorescent dyes. (c) Chemical structures of chemiluminescent compounds with high brightness.

(a)

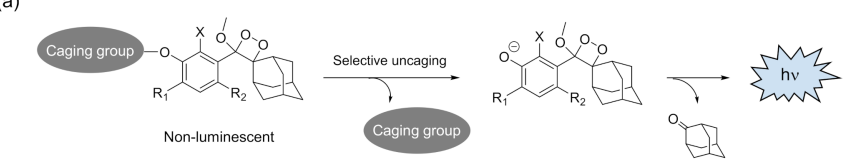

(b)
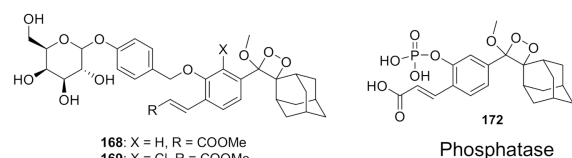

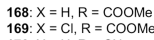
170: $X=H, R=C N$
$171: X=C I, R=C N$

Phosphatase

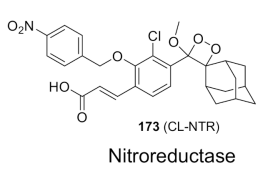

$\beta$-galactosidase
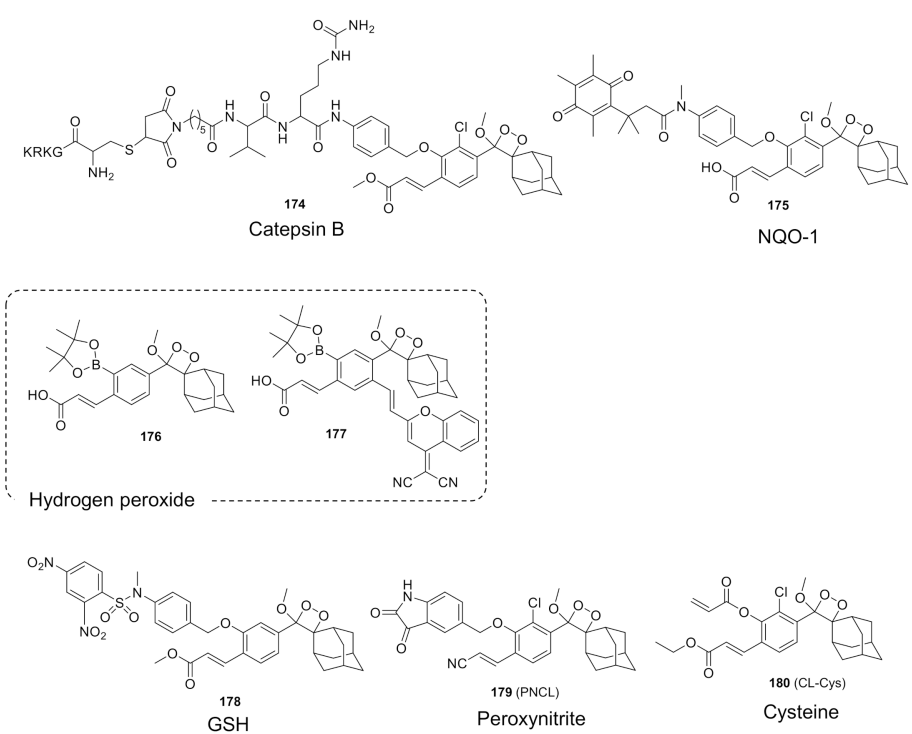

Figure 13. Cont. 


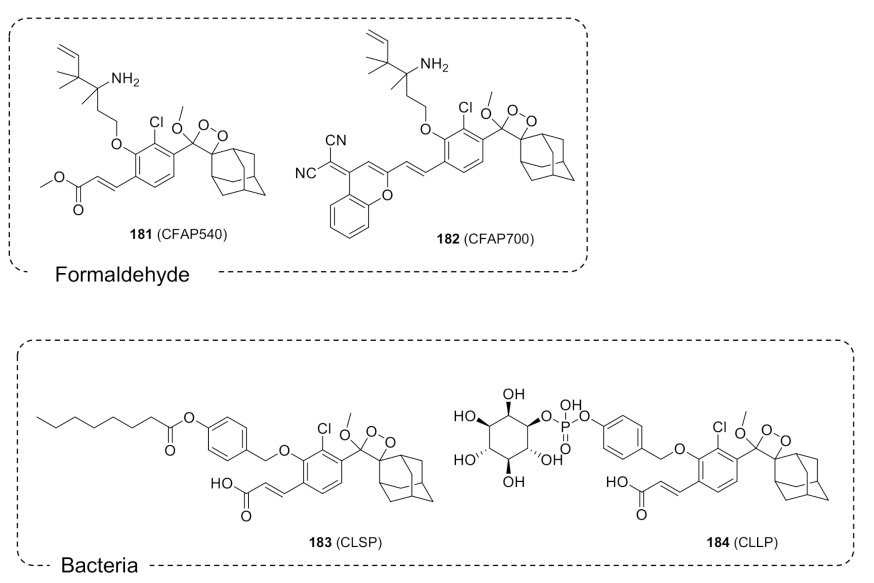

Figure 13. Chemiluminescence probes based on the caged strategy. (a) The design strategy of caged compounds. (b) Chemical structures of chemiluminescence probes.

While chemiluminescence and bioluminescence show almost similar sensitivities, bioluminescence requires luciferase for measurement, which has both advantages and disadvantages. For experiments investigating gene expression or cell tracking, a reporter enzyme is required. In such a case, bioluminescence is more suitable because luciferase can be used directly as a reporter enzyme. In principle, no signal is detected from cells that do not express luciferase, so a highly sensitive measurement is possible. On the other hand, in the case of the development of imaging probes for biomolecules, luciferase is required for the bioluminescence measurement, which then requires the preparation of transfected cells and transgenic animals expressing luciferase, leading to less flexibility and higher costs. The chemiluminescence probes do not have such problems, thus allowing us to establish a simpler experimental system, which may become an important alternative imaging tool in the future.

\section{Summary}

Since luminescence imaging has a lower background signal compared to fluorescence imaging, it will continue to be used, especially for in in vivo imaging. As outlined in this review, various studies on bioluminescence imaging reagents have been conducted in the last two decades, and there has been a great deal of interest in developing substrates for in vivo imaging and bioluminescence probes for detecting biomolecules and in vivo events. In addition, a very large number of caged luciferin-based bioluminescence probes have been developed and applied to in vivo imaging. On the other hand, chemiluminescence probes based on the 1,2-dioxetane scaffold with higher brightness have also been rapidly developed and have applied to in vivo imaging. It is expected that bioluminescence and chemiluminescence imaging will continue to be used as powerful analytical tools, and that new biological findings will be discovered from these methods.

Author Contributions: Conceptualization, H.T.; writing—original draft preparation, H.T.; writingreview and editing, H.T.; visualization, H.T. The author has read and agreed to the published version of the manuscript.

Funding: This study was supported by JSPS KAKENHI grants 19K07010 to H.T.

Conflicts of Interest: The author declares no conflict of interest.

\section{References}

1. Prescher, J.A.; Contag, C.H. Guided by the light: Visualizing biomolecular processes in living animals with bioluminescence. Curr. Opin. Chem. Biol. 2010, 14, 80-89. [CrossRef]

2. Badr, C.E.; Tannous, B.A. Bioluminescence imaging: Progress and applications. Trends Biotechnol. 2011, 29, 624-633. [CrossRef]

3. Hananya, N.; Shabat, D. Recent advances and challenges in luminescent imaging: Bright outlook for chemiluminescence of dioxetanes in water. ACS Cent. Sci. 2019, 5, 949-959. [CrossRef] [PubMed] 
4. Weissleder, R. A clearer vision for in vivo imaging. Nat. Biotechnol. 2001, 19, 316-317. [CrossRef] [PubMed]

5. Antaris, A.L.; Chen, H.; Cheng, K.; Sun, Y.; Hong, G.; Qu, C.; Diao, S.; Deng, Z.; Hu, X.; Zhang, B.; et al. A small-molecule dye for nir-ii imaging. Nat. Mater. 2016, 15, 235-242. [CrossRef] [PubMed]

6. Hemmer, E.; Benayas, A.; Legare, F.; Vetrone, F. Exploiting the biological windows: Current perspectives on fluorescent bioprobes emitting above $1000 \mathrm{~nm}$. Nanoscale Horiz. 2016, 1, 168-184. [CrossRef] [PubMed]

7. Zhao, J.; Zhong, D.; Zhou, S. Nir-i-to-nir-ii fluorescent nanomaterials for biomedical imaging and cancer therapy. J. Mater. Chem. B 2018, 6, 349-365. [CrossRef] [PubMed]

8. Lu, L.; Li, B.; Ding, S.; Fan, Y.; Wang, S.; Sun, C.; Zhao, M.; Zhao, C.X.; Zhang, F. Nir-ii bioluminescence for in vivo high contrast imaging and in situ atp-mediated metastases tracing. Nat. Commun. 2020, 11, 4192. [CrossRef]

9. Yao, Z.; Zhang, B.S.; Prescher, J.A. Advances in bioluminescence imaging: New probes from old recipes. Curr. Opin. Chem. Biol. 2018, 45, 148-156. [CrossRef]

10. Jiang, T.; Du, L.; Li, M. Lighting up bioluminescence with coelenterazine: Strategies and applications. Photochem. Photobiol. Sci. 2016, 15, 466-480. [CrossRef]

11. Krasitskaya, V.V.; Bashmakova, E.E.; Frank, L.A. Coelenterazine-dependent luciferases as a powerful analytical tool for research and biomedical applications. Int. J. Mol. Sci. 2020, 21, 7465. [CrossRef]

12. Gregor, C.; Gwosch, K.C.; Sahl, S.J.; Hell, S.W. Strongly enhanced bacterial bioluminescence with the ilux operon for single-cell imaging. Proc. Natl. Acad. Sci. USA 2018, 115, 962-967. [CrossRef]

13. Lee, J.; Muller, F.; Visser, A. The sensitized bioluminescence mechanism of bacterial luciferase. Photochem. Photobiol. 2019, 95, 679-704. [CrossRef]

14. Takakura, H.; Kojima, R.; Ozawa, T.; Nagano, T.; Urano, Y. Development of 5'- and 7'-substituted luciferin analogues as acid-tolerant substrates of firefly luciferase. Chembiochem 2012, 13, 1424-1427. [CrossRef] [PubMed]

15. Oliveira, G.; Viviani, V.R. Temperature effect on the bioluminescence spectra of firefly luciferases: Potential applicability for ratiometric biosensing of temperature and ph. Photochem. Photobiol. Sci. 2019, 18, 2682-2687. [CrossRef] [PubMed]

16. Ugarova, N.N.; Brovko, L.Y. Protein structure and bioluminescent spectra for firefly bioluminescence. Luminescence 2002, 17, 321-330. [CrossRef] [PubMed]

17. Branchini, B.R.; Magyar, R.A.; Murtiashaw, M.H.; Anderson, S.M.; Helgerson, L.C.; Zimmer, M. Site-directed mutagenesis of firefly luciferase active site amino acids: A proposed model for bioluminescence color. Biochemistry 1999, 38, 13223-13230. [CrossRef]

18. Branchini, B.R.; Murtiashaw, M.H.; Magyar, R.A.d.M. The role of lysine 529, a conserved residue of the acyl-adenylate-forming enzyme superfamily, in firefly luciferase. Biochemistry 2000, 39, 5433-5440. [CrossRef]

19. Branchini, B.R.; Magyar, R.A.; Murtiashaw, M.H.; Portier, N.C. The role of active site residue arginine 218 in firefly luciferase bioluminescence. Biochemistry 2001, 40, 2410-2418. [CrossRef] [PubMed]

20. Branchini, B.R.; Southworth, T.L.; Murtiashaw, M.H.; Boije, H.; Fleet, S.E. A mutagenesis study of the putative luciferin binding site residues of firefly luciferase. Biochemistry 2003, 42, 10429-10436. [CrossRef] [PubMed]

21. Nishiguchi, T.; Yamada, T.; Nasu, Y.; Ito, M.; Yoshimura, H.; Ozawa, T. Development of red-shifted mutants derived from luciferase of brazilian click beetle pyrearinus termitilluminans. J. Biomed. Opt. 2015, 20, 101205. [CrossRef]

22. Hirano, T.; Hasumi, Y.; Ohtsuka, K.; Maki, S.; Niwa, H.; Yamaji, M.; Hashizume, D. Spectroscopic studies of the light-color modulation mechanism of firefly (beetle) bioluminescence. J. Am. Chem. Soc. 2009, 131, 2385-2396. [CrossRef] [PubMed]

23. Naumov, P.; Ozawa, Y.; Ohkubo, K.; Fukuzumi, S. Structure and spectroscopy of oxyluciferin, the light emitter of the firefly bioluminescence. J. Am. Chem. Soc. 2009, 131, 11590-11605. [CrossRef] [PubMed]

24. Naumov, P.; Kochunnoonny, M. Spectral-structural effects of the keto-enol-enolate and phenol-phenolate equilibria of oxyluciferin. J. Am. Chem. Soc. 2010, 132, 11566-11579. [CrossRef]

25. Rebarz, M.; Kukovec, B.-M.; Maltsev, O.V.; Ruckebusch, C.; Hintermann, L.; Naumov, P.; Sliwa, M. Deciphering the protonation and tautomeric equilibria of firefly oxyluciferin by molecular engineering and multivariate curve resolution. Chem. Sci. 2013, 4, 3803-3809. [CrossRef]

26. Branchini, B.R.; Ablamsky, D.M.; Rosenberg, J.C. Chemically modified firefly luciferase is an efficient source of near-infrared light. Bioconjug. Chem. 2010, 21, 2023-2030. [CrossRef]

27. Shcherbakova, D.M.; Verkhusha, V.V. Near-infrared fluorescent proteins for multicolor in vivo imaging. Nat. Methods 2013, 10, 751-754. [CrossRef]

28. Arai, R.; Nakagawa, H.; Kitayama, A.; Ueda, H.; Nagamune, T. Detection of protein-protein interaction by bioluminescence resonance energy transfer from firefly luciferase to red fluorescent protein. J. Biosci. Bioeng. 2002, 94, 362-364. [CrossRef]

29. Iglesias, P.; Costoya, J.A. A novel bret-based genetically encoded biosensor for functional imaging of hypoxia. Biosens. Bioelectron. 2009, 24, 3126-3130. [CrossRef]

30. Mezzanotte, L.; Blankevoort, V.; Lowik, C.W.; Kaijzel, E.L. A novel luciferase fusion protein for highly sensitive optical imaging: From single-cell analysis to in vivo whole-body bioluminescence imaging. Anal. Bioanal. Chem. 2014, 406, 5727-5734. [CrossRef]

31. White, E.H.; Wörther, H.; Field, G.F.; McElroy, W.D. Analogs of firefly luciferin. J. Org. Chem. 1965, 30, 2344-2348. [CrossRef]

32. White, E.H.; Worther, H. Analogs of firefly luciferin. 3. J. Org. Chem. 1966, 31, 1484-1488. [CrossRef] [PubMed]

33. Denburg, J.L.; Lee, R.T.; McElroy, W.D. Substrate-binding properties of firefly luciferase. Arch. Biochem. Biophys. 1969, 134, 381-394. [CrossRef] 
34. White, E.H.; Wörther, H.; Seliger, H.H.; McElroy, W.D. Amino analogs of firefly luciferin and biological activity thereof1. J. Am. Chem. Soc. 1966, 88, 2015-2019. [CrossRef]

35. Reddy, G.R.; Thompson, W.C.; Miller, S.C. Robust light emission from cyclic alkylaminoluciferin substrates for firefly luciferase. J. Am. Chem Soc. 2010, 132, 13586-13587. [CrossRef] [PubMed]

36. Takakura, H.; Kojima, R.; Urano, Y.; Terai, T.; Hanaoka, K.; Nagano, T. Aminoluciferins as functional bioluminogenic substrates of firefly luciferase. Chem. Asian J. 2011, 6, 1800-1810. [CrossRef]

37. Sharma, D.K.; Adams, S.T., Jr.; Liebmann, K.L.; Miller, S.C. Rapid access to a broad range of 6'-substituted firefly luciferin analogues reveals surprising emitters and inhibitors. Org. Lett. 2017, 19, 5836-5839. [CrossRef] [PubMed]

38. Wu, W.; Su, J.; Tang, C.; Bai, H.; Ma, Z.; Zhang, T.; Yuan, Z.; Li, Z.; Zhou, W.; Zhang, H.; et al. Cybluc: An effective aminoluciferin derivative for deep bioluminescence imaging. Anal. Chem. 2017, 89, 4808-4816. [CrossRef]

39. Mofford, D.M.; Reddy, G.R.; Miller, S.C. Aminoluciferins extend firefly luciferase bioluminescence into the near-infrared and can be preferred substrates over d-luciferin. J. Am. Chem. Soc. 2014, 136, 13277-13282. [CrossRef]

40. Branchini, B.R. Chemical synthesis of firefly luciferin analogs and inhibitors. Methods Enzymol. 2000, 305, $188-195$.

41. Takakura, H.; Sasakura, K.; Ueno, T.; Urano, Y.; Terai, T.; Hanaoka, K.; Tsuboi, T.; Nagano, T. Development of luciferin analogues bearing an amino group and their application as bret donors. Chem. Asian J. 2010, 5, 2053-2061. [CrossRef]

42. McCutcheon, D.C.; Paley, M.A.; Steinhardt, R.C.; Prescher, J.A. Expedient synthesis of electronically modified luciferins for bioluminescence imaging. J. Am. Chem. Soc. 2012, 134, 7604-7607. [CrossRef]

43. Conley, N.R.; Dragulescu-Andrasi, A.; Rao, J.; Moerner, W.E. A selenium analogue of firefly d-luciferin with red-shifted bioluminescence emission. Angew. Chem. Int. Ed. 2012, 51, 3350-3353. [CrossRef]

44. Ioka, S.; Saitoh, T.; Iwano, S.; Suzuki, K.; Maki, S.A.; Miyawaki, A.; Imoto, M.; Nishiyama, S. Synthesis of firefly luciferin analogues and evaluation of the luminescent properties. Chem. Eur. J. 2016, 22, 9330-9337. [CrossRef] [PubMed]

45. Zhang, B.S.; Jones, K.A.; McCutcheon, D.C.; Prescher, J.A. Pyridone luciferins and mutant luciferases for bioluminescence imaging. Chembiochem 2018, 19, 470-477. [CrossRef]

46. Pirrung, M.C.; Biswas, G.; De Howitt, N.; Liao, J. Synthesis and bioluminescence of difluoroluciferin. Bioorg. Med. Chem. Lett. 2014, 24, 4881-4883. [CrossRef] [PubMed]

47. Steinhardt, R.C.; Rathbun, C.M.; Krull, B.T.; Yu, J.M.; Yang, Y.; Nguyen, B.D.; Kwon, J.; McCutcheon, D.C.; Jones, K.A.; Furche, F.; et al. Brominated luciferins are versatile bioluminescent probes. Chembiochem 2017, 18, 96-100. [CrossRef] [PubMed]

48. Steinhardt, R.C.; O'Neill, J.M.; Rathbun, C.M.; McCutcheon, D.C.; Paley, M.A.; Prescher, J.A. Design and synthesis of an alkynyl luciferin analogue for bioluminescence imaging. Chem. Eur. J. 2016, 22, 3671-3675. [CrossRef]

49. Ikeda, Y.; Saitoh, T.; Niwa, K.; Nakajima, T.; Kitada, N.; Maki, S.A.; Sato, M.; Citterio, D.; Nishiyama, S.; Suzuki, K. An allylated firefly luciferin analogue with luciferase specific response in living cells. Chem. Commun. 2018, 54, 1774-1777. [CrossRef]

50. Jones, K.A.; Porterfield, W.B.; Rathbun, C.M.; McCutcheon, D.C.; Paley, M.A.; Prescher, J.A. Orthogonal luciferase-luciferin pairs for bioluminescence imaging. J. Am. Chem. Soc. 2017, 139, 2351-2358. [CrossRef]

51. Iwano, S.; Obata, R.; Miura, C.; Kiyama, M.; Hama, K.; Nakamura, M.; Amano, Y.; Kojima, S.; Hirano, T.; Maki, S.; et al. Development of simple firefly luciferin analogs emitting blue, green, red, and near-infrared biological window light. Tetrahedron 2013, 69, 3847-3856. [CrossRef]

52. Kitada, N.; Saitoh, T.; Ikeda, Y.; Iwano, S.; Obata, R.; Niwa, H.; Hirano, T.; Miyawaki, A.; Suzuki, K.; Nishiyama, S.; et al. Toward bioluminescence in the near-infrared region: Tuning the emission wavelength of firefly luciferin analogues by allyl substitution. Tetrahedron Lett. 2018, 59, 1087-1090. [CrossRef]

53. Saito, R.; Kuchimaru, T.; Higashi, S.; Lu, S.W.; Kiyama, M.; Iwano, S.; Obata, R.; Hirano, T.; Kizaka-Kondoh, S.; Maki, S.A. Synthesis and luminescence properties of near-infrared $\mathrm{n}$-heterocyclic luciferin analogues for in vivo optical imaging. Bull. Chem. Soc. Jpn. 2019, 92, 608-618. [CrossRef]

54. Kiyama, M.; Iwano, S.; Otsuka, S.; Lu, S.W.; Obata, R.; Miyawaki, A.; Hirano, T.; Maki, S.A. Quantum yield improvement of red-light-emitting firefly luciferin analogues for in vivo bioluminescence imaging. Tetrahedron 2018, 74, 652-660. [CrossRef]

55. Ikeda, Y.; Nomoto, T.; Hiruta, Y.; Nishiyama, N.; Citterio, D. Ring-fused firefly luciferins: Expanded palette of near-infrared emitting bioluminescent substrates. Anal. Chem. 2020, 92, 4235-4243. [CrossRef]

56. Jathoul, A.P.; Grounds, H.; Anderson, J.C.; Pule, M.A. A dual-color far-red to near-infrared firefly luciferin analogue designed for multiparametric bioluminescence imaging. Angew. Chem. Int. Ed. 2014, 53, 13059-13063. [CrossRef] [PubMed]

57. Miura, C.; Kiyama, M.; Iwano, S.; Ito, K.; Obata, R.; Hirano, T.; Maki, S.; Niwa, H. Synthesis and luminescence properties of biphenyl-type firefly luciferin analogs with a new, near-infrared light-emitting bioluminophore. Tetrahedron 2013, 69, $9726-9734$. [CrossRef]

58. Hall, M.P.; Woodroofe, C.C.; Wood, M.G.; Que, I.; Van't Root, M.; Ridwan, Y.; Shi, C.; Kirkland, T.A.; Encell, L.P.; Wood, K.V.; et al. Click beetle luciferase mutant and near infrared naphthyl-luciferins for improved bioluminescence imaging. Nat. Commun. 2018, 9, 1-12. [CrossRef] [PubMed]

59. Kojima, R.; Takakura, H.; Ozawa, T.; Tada, Y.; Nagano, T.; Urano, Y. Rational design and development of near-infrared-emitting firefly luciferins available in vivo. Angew. Chem. Int. Ed. 2013, 52, 1175-1179. [CrossRef] [PubMed]

60. Harwood, K.R.; Mofford, D.M.; Reddy, G.R.; Miller, S.C. Identification of mutant firefly luciferases that efficiently utilize aminoluciferins. Chem. Biol. 2011, 18, 1649-1657. [CrossRef] 
61. Iwano, S.; Sugiyama, M.; Hama, H.; Watakabe, A.; Hasegawa, N.; Kuchimaru, T.; Tanaka, K.Z.; Takahashi, M.; Ishida, Y.; Hata, J.; et al. Single-cell bioluminescence imaging of deep tissue in freely moving animals. Science 2018, 359, 935-939. [CrossRef]

62. Kobayashi, H.; Ogawa, M.; Alford, R.; Choyke, P.L.; Urano, Y. New strategies for fluorescent probe design in medical diagnostic imaging. Chem. Rev. 2010, 110, 2620-2640. [CrossRef]

63. Zhang, W.; Ma, Z.; Du, L.; Li, M. Design strategy for photoinduced electron transfer-based small-molecule fluorescent probes of biomacromolecules. Analyst 2014, 139, 2641-2649. [CrossRef] [PubMed]

64. Kowada, T.; Maeda, H.; Kikuchi, K. Bodipy-based probes for the fluorescence imaging of biomolecules in living cells. Chem. Soc. Rev. 2015, 44, 4953-4972. [CrossRef]

65. Takakura, H.; Kojima, R.; Kamiya, M.; Kobayashi, E.; Komatsu, T.; Ueno, T.; Terai, T.; Hanaoka, K.; Nagano, T.; Urano, Y. New class of bioluminogenic probe based on bioluminescent enzyme-induced electron transfer: Biolet. J. Am. Chem. Soc. 2015, 137, 4010-4013. [CrossRef]

66. Amess, R.; Baggett, N.; Darby, P.R.; Goode, A.R.; Vickers, E.E. Synthesis of luciferin glycosides as substrates for novel ultrasensitive enzyme assays. Carbohydr. Res. 1990, 205, 225-233. [CrossRef]

67. Isobe, M.; Sugiyama, Y.; Ito, T.; Ohtani, I.I.; Toya, Y.; Nishigohri, Y.; Takai, A. New analysis method for protein phosphatase type 2a inhibitors using the firefly bioluminescence system. Biosci. Biotechnol. Biochem. 1995, 59, 2235-2238. [CrossRef]

68. Zhou, W.; Andrews, C.; Liu, J.; Shultz, J.W.; Valley, M.P.; Cali, J.J.; Hawkins, E.M.; Klaubert, D.H.; Bulleit, R.F.; Wood, K.V. Self-cleavable bioluminogenic luciferin phosphates as alkaline phosphatase reporters. Chembiochem 2008, 9, 714-718. [CrossRef] [PubMed]

69. Yao, H.; So, M.K.; Rao, J. A bioluminogenic substrate for in vivo imaging of beta-lactamase activity. Angew. Chem. Int. Ed. 2007, 46, 7031-7034. [CrossRef]

70. Zhou, W.; Valley, M.P.; Shultz, J.; Hawkins, E.M.; Bernad, L.; Good, T.; Good, D.; Riss, T.L.; Klaubert, D.H.; Wood, K.V. New bioluminogenic substrates for monoamine oxidase assays. J. Am. Chem. Soc. 2006, 128, 3122-3123. [CrossRef]

71. Mofford, D.M.; Adams, S.T., Jr.; Reddy, G.S.; Reddy, G.R.; Miller, S.C. Luciferin amides enable in vivo bioluminescence detection of endogenous fatty acid amide hydrolase activity. J. Am. Chem. Soc. 2015, 137, 8684-8687. [CrossRef]

72. Porterfield, W.B.; Jones, K.A.; McCutcheon, D.C.; Prescher, J.A. A “caged” luciferin for imaging cell-cell contacts. J. Am. Chem. Soc. 2015, 137, 8656-8659. [CrossRef]

73. Vorobyeva, A.G.; Stanton, M.; Godinat, A.; Lund, K.B.; Karateev, G.G.; Francis, K.P.; Allen, E.; Gelovani, J.G.; McCormack, E.; Tangney, M.; et al. Development of a bioluminescent nitroreductase probe for preclinical imaging. PLoS ONE 2015, 10, e0131037. [CrossRef]

74. Wong, R.H.; Kwong, T.; Yau, K.H.; Au-Yeung, H.Y. Real time detection of live microbes using a highly sensitive bioluminescent nitroreductase probe. Chem. Commun. 2015, 51, 4440-4442. [CrossRef] [PubMed]

75. Feng, P.; Zhang, H.; Deng, Q.; Liu, W.; Yang, L.; Li, G.; Chen, G.; Du, L.; Ke, B.; Li, M. Real-time bioluminescence imaging of nitroreductase in mouse model. Anal. Chem. 2016, 88, 5610-5614. [CrossRef] [PubMed]

76. Meisenheimer, P.L.; Uyeda, H.T.; Ma, D.; Sobol, M.; McDougall, M.G.; Corona, C.; Simpson, D.; Klaubert, D.H.; Cali, J.J. Proluciferin acetals as bioluminogenic substrates for cytochrome p450 activity and probes for cyp3a inhibition. Drug Metab. Dispos. 2011, 39, 2403-2410. [CrossRef] [PubMed]

77. Wang, J.; Lee, T.S.; Zhang, Z.; Tung, C.H. A bioluminogenic probe for monitoring tyrosinase activity. Chem. Asian J. 2017, 12, 397-400. [CrossRef]

78. Li, S.; Hu, R.; Wang, S.; Guo, X.; Zeng, Y.; Li, Y.; Yang, G. Specific imaging of tyrosinase in vivo with 3-hydroxybenzyl caged d-luciferins. Anal. Chem. 2018, 90, 9296-9300. [CrossRef] [PubMed]

79. Li, S.; Hu, R.; Yang, C.; Zhang, X.; Zeng, Y.; Wang, S.; Guo, X.; Li, Y.; Cai, X.; Li, S.; et al. An ultrasensitive bioluminogenic probe of gamma-glutamyltranspeptidase in vivo and in human serum for tumor diagnosis. Biosens. Bioelectron. 2017, 98, 325-329. [CrossRef] [PubMed]

80. Lin, Y.; Gao, Y.; Ma, Z.; Jiang, T.; Zhou, X.; Li, Z.; Qin, X.; Huang, Y.; Du, L.; Li, M. Bioluminescence probe for gamma-glutamyl transpeptidase detection in vivo. Bioorg. Med. Chem. 2018, 26, 134-140. [CrossRef] [PubMed]

81. Zhou, W.; Shultz, J.W.; Murphy, N.; Hawkins, E.M.; Bernad, L.; Good, T.; Moothart, L.; Frackman, S.; Klaubert, D.H.; Bulleit, R.F.; et al. Electrophilic aromatic substituted luciferins as bioluminescent probes for glutathione s-transferase assays. Chem. Commun. 2006, 4620-4622. [CrossRef]

82. Lin, Y.; Gao, Y.; Ma, Z.; Li, Z.; Tang, C.; Qin, X.; Zhang, Z.; Wang, G.; Du, L.; Li, M. Bioluminescent probe for detection of starvation-induced pantetheinase upregulation. Anal. Chem. 2018, 90, 9545-9550. [CrossRef]

83. Monsees, T.; Miska, W.; Geiger, R. Synthesis and characterization of a bioluminogenic substrate for alpha-chymotrypsin. Anal. Biochem. 1994, 221, 329-334. [CrossRef] [PubMed]

84. Shah, K.; Tung, C.H.; Breakefield, X.O.; Weissleder, R. In vivo imaging of s-trail-mediated tumor regression and apoptosis. Mol. Ther. 2005, 11, 926-931. [CrossRef] [PubMed]

85. Dragulescu-Andrasi, A.; Liang, G.; Rao, J. In vivo bioluminescence imaging of furin activity in breast cancer cells using bioluminogenic substrates. Bioconjug. Chem. 2009, 20, 1660-1666. [CrossRef] [PubMed]

86. Lin, Y.; Ma, Z.; Li, Z.; Gao, Y.; Qin, X.; Zhang, Z.; Wang, G.; Du, L.; Li, M. Bioluminescent probe for monitoring endogenous fibroblast activation protein-alpha. Anal. Chem. 2019, 91, 14873-14878. [CrossRef] 
87. Van de Bittner, G.C.; Dubikovskaya, E.A.; Bertozzi, C.R.; Chang, C.J. In vivo imaging of hydrogen peroxide production in a murine tumor model with a chemoselective bioluminescent reporter. Proc. Natl. Acad. Sci. USA 2010, 107, 21316-21321. [CrossRef]

88. Wu, W.; Li, J.; Chen, L.; Ma, Z.; Zhang, W.; Liu, Z.; Cheng, Y.; Du, L.; Li, M. Bioluminescent probe for hydrogen peroxide imaging in vitro and in vivo. Anal. Chem. 2014, 86, 9800-9806. [CrossRef]

89. Chen, P.; Zheng, Z.; Zhu, Y.; Dong, Y.; Wang, F.; Liang, G. Bioluminescent turn-on probe for sensing hypochlorite in vitro and in tumors. Anal. Chem. 2017, 89, 5693-5696. [CrossRef]

90. Tang, C.; Gao, Y.; Liu, T.; Lin, Y.; Zhang, X.; Zhang, C.; Li, X.; Zhang, T.; Du, L.; Li, M. Bioluminescent probe for detecting endogenous hypochlorite in living mice. Org. Biomol. Chem. 2018, 16, 645-651. [CrossRef]

91. Li, J.B.; Chen, L.; Wang, Q.; Liu, H.W.; Hu, X.X.; Yuan, L.; Zhang, X.B. A bioluminescent probe for imaging endogenous peroxynitrite in living cells and mice. Anal. Chem. 2018, 90, 4167-4173. [CrossRef]

92. Tian, X.; Li, Z.; Lau, C.; Lu, J. Visualization of in vivo hydrogen sulfide production by a bioluminescence probe in cancer cells and nude mice. Anal. Chem. 2015, 87, 11325-11331. [CrossRef] [PubMed]

93. Ke, B.; Wu, W.; Liu, W.; Liang, H.; Gong, D.; Hu, X.; Li, M. Bioluminescence probe for detecting hydrogen sulfide in vivo. Anal. Chem. 2016, 88, 592-595. [CrossRef] [PubMed]

94. Li, J.B.; Wang, Q.; Liu, H.W.; Yuan, L.; Zhang, X.B. A bioluminescent probe for imaging endogenous hydrogen polysulfides in live cells and a murine model of bacterial infection. Chem. Commun. 2019, 55, 4487-4490. [CrossRef] [PubMed]

95. Zhang, M.; Wang, L.; Zhao, Y.; Wang, F.; Wu, J.; Liang, G. Using bioluminescence turn-on to detect cysteine in vitro and in vivo. Anal. Chem. 2018, 90, 4951-4954. [CrossRef] [PubMed]

96. Zhang, L.; Shi, Y.; Sheng, Z.; Zhang, Y.; Kai, X.; Li, M.; Yin, X. Bioluminescence imaging of selenocysteine in vivo with a highly sensitive probe. ACS Sens. 2019, 4, 3147-3155. [CrossRef]

97. Hemmi, M.; Ikeda, Y.; Shindo, Y.; Nakajima, T.; Nishiyama, S.; Oka, K.; Sato, M.; Hiruta, Y.; Citterio, D.; Suzuki, K. Highly sensitive bioluminescent probe for thiol detection in living cells. Chem. Asian J. 2018, 13, 648-655. [CrossRef]

98. Heffern, M.C.; Park, H.M.; Au-Yeung, H.Y.; Van de Bittner, G.C.; Ackerman, C.M.; Stahl, A.; Chang, C.J. In vivo bioluminescence imaging reveals copper deficiency in a murine model of nonalcoholic fatty liver disease. Proc. Natl. Acad. Sci. USA 2016, 113, 14219-14224. [CrossRef]

99. Zheng, Z.; Wang, L.; Tang, W.; Chen, P.; Zhu, H.; Yuan, Y.; Li, G.; Zhang, H.; Liang, G. Hydrazide d-luciferin for in vitro selective detection and intratumoral imaging of $\mathrm{cu}(2$.). Biosens. Bioelectron. 2016, 83, 200-204. [CrossRef]

100. Ke, B.; Chen, H.; Cui, Y.; Ma, L.; Liu, Y.; Hu, X.; Bai, Y.; Du, L.; Li, M. A bioluminescent strategy for imaging palladium in living cells and animals with chemoselective probes based on luciferin-luciferase system. Talanta 2019, 194, 925-929. [CrossRef] [PubMed]

101. Aron, A.T.; Heffern, M.C.; Lonergan, Z.R.; Vander Wal, M.N.; Blank, B.R.; Spangler, B.; Zhang, Y.; Park, H.M.; Stahl, A.; Renslo, A.R.; et al. In vivo bioluminescence imaging of labile iron accumulation in a murine model of acinetobacter baumannii infection. Proc. Natl. Acad. Sci. USA 2017, 114, 12669-12674. [CrossRef] [PubMed]

102. Ke, B.; Wu, W.; Wei, L.; Wu, F.; Chen, G.; He, G.; Li, M. Cell and in vivo imaging of fluoride ion with highly selective bioluminescent probes. Anal. Chem. 2015, 87, 9110-9113. [CrossRef] [PubMed]

103. Van de Bittner, G.C.; Bertozzi, C.R.; Chang, C.J. Strategy for dual-analyte luciferin imaging: In vivo bioluminescence detection of hydrogen peroxide and caspase activity in a murine model of acute inflammation. J. Am. Chem. Soc. 2013, 135, 1783-1795. [CrossRef] [PubMed]

104. Gao, Y.; Lin, Y.; Liu, T.; Chen, H.; Yang, X.; Tian, C.; Du, L.; Li, M. Bioluminescent probe for tumor hypoxia detection via cyp450 reductase in living animals. Anal. Chem. 2017, 89, 12488-12493. [CrossRef] [PubMed]

105. Shao, Q.; Jiang, T.; Ren, G.; Cheng, Z.; Xing, B. Photoactivable bioluminescent probes for imaging luciferase activity. Chem. Commun. 2009, 4028-4030. [CrossRef]

106. Cohen, A.S.; Dubikovskaya, E.A.; Rush, J.S.; Bertozzi, C.R. Real-time bioluminescence imaging of glycans on live cells. J. Am. Chem. Soc. 2010, 132, 8563-8565. [CrossRef]

107. Henkin, A.H.; Cohen, A.S.; Dubikovskaya, E.A.; Park, H.M.; Nikitin, G.F.; Auzias, M.G.; Kazantzis, M.; Bertozzi, C.R.; Stahl, A. Real-time noninvasive imaging of fatty acid uptake in vivo. ACS Chem. Biol. 2012, 7, 1884-1891. [CrossRef]

108. Kojima, R.; Takakura, H.; Kamiya, M.; Kobayashi, E.; Komatsu, T.; Ueno, T.; Terai, T.; Hanaoka, K.; Nagano, T.; Urano, Y. Development of a sensitive bioluminogenic probe for imaging highly reactive oxygen species in living rats. Angew. Chem. Int. Ed. 2015, 54, 14768-14771. [CrossRef] [PubMed]

109. Dodeigne, C. Chemiluminescence as diagnostic tool. A review. Talanta 2000, 51, 415-439. [CrossRef]

110. Matsumoto, M. Advanced chemistry of dioxetane-based chemiluminescent substrates originating from bioluminescence. J. Photochem. Photobiol. C Photochem. Rev. 2004, 5, 27-53. [CrossRef]

111. Hananya, N.; Eldar Boock, A.; Bauer, C.R.; Satchi-Fainaro, R.; Shabat, D. Remarkable enhancement of chemiluminescent signal by dioxetane-fluorophore conjugates: Turn-on chemiluminescence probes with color modulation for sensing and imaging. J. Am. Chem. Soc. 2016, 138, 13438-13446. [CrossRef]

112. Green, O.; Eilon, T.; Hananya, N.; Gutkin, S.; Bauer, C.R.; Shabat, D. Opening a gateway for chemiluminescence cell imaging: Distinctive methodology for design of bright chemiluminescent dioxetane probes. ACS Cent. Sci. 2017, 3, 349-358. [CrossRef] [PubMed] 
113. Green, O.; Gnaim, S.; Blau, R.; Eldar-Boock, A.; Satchi-Fainaro, R.; Shabat, D. Near-infrared dioxetane luminophores with direct chemiluminescence emission mode. J. Am. Chem. Soc. 2017, 139, 13243-13248. [CrossRef] [PubMed]

114. Hananya, N.; Reid, J.P.; Green, O.; Sigman, M.S.; Shabat, D. Rapid chemiexcitation of phenoxy-dioxetane luminophores yields ultrasensitive chemiluminescence assays. Chem. Sci. 2019, 10, 1380-1385. [CrossRef]

115. Eilon-Shaffer, T.; Roth-Konforti, M.; Eldar-Boock, A.; Satchi-Fainaro, R.; Shabat, D. Ortho-chlorination of phenoxy 1,2-dioxetane yields superior chemiluminescent probes for in vitro and in vivo imaging. Org. Biomol. Chem. 2018, 16, 1708-1712. [CrossRef]

116. Sun, J.; Hu, Z.; Wang, R.; Zhang, S.; Zhang, X. A highly sensitive chemiluminescent probe for detecting nitroreductase and imaging in living animals. Anal. Chem. 2019, 91, 1384-1390. [CrossRef]

117. Roth-Konforti, M.E.; Bauer, C.R.; Shabat, D. Unprecedented sensitivity in a probe for monitoring cathepsin b: Chemiluminescence microscopy cell-imaging of a natively expressed enzyme. Angew. Chem. Int. Ed. 2017, 56, 15633-15638. [CrossRef] [PubMed]

118. Son, S.; Won, M.; Green, O.; Hananya, N.; Sharma, A.; Jeon, Y.; Kwak, J.H.; Sessler, J.L.; Shabat, D.; Kim, J.S. Chemiluminescent probe for the in vitro and in vivo imaging of cancers over-expressing nqo1. Angew. Chem. Int. Ed. 2019, 58, 1739-1743. [CrossRef]

119. Cao, J.; An, W.; Reeves, A.G.; Lippert, A.R. A chemiluminescent probe for cellular peroxynitrite using a self-immolative oxidative decarbonylation reaction. Chem. Sci. 2018, 9, 2552-2558. [CrossRef] [PubMed]

120. Sun, J.; Hu, Z.; Zhang, S.; Zhang, X. A novel chemiluminescent probe based on 1,2-dioxetane scaffold for imaging cysteine in living mice. ACS Sens. 2019, 4, 87-92. [CrossRef]

121. Bruemmer, K.J.; Green, O.; Su, T.A.; Shabat, D.; Chang, C.J. Chemiluminescent probes for activity-based sensing of formaldehyde released from folate degradation in living mice. Angew. Chem. Int. Ed. 2018, 57, 7508-7512. [CrossRef] [PubMed]

122. Roth-Konforti, M.; Green, O.; Hupfeld, M.; Fieseler, L.; Heinrich, N.; Ihssen, J.; Vorberg, R.; Wick, L.; Spitz, U.; Shabat, D. Ultrasensitive detection of salmonella and listeria monocytogenes by small-molecule chemiluminescence probes. Angew. Chem. Int. Ed. 2019, 58, 10361-10367. [CrossRef] [PubMed] 